GEOLOGICAL SURVEY

COMPUTER CONTRIBUTION

\author{
NUMBER 1 \\ Weighted Triangulation Adjustment \\ by \\ Walter L. Anderson
}
Computer Center Division
Washington, D. C. 1969

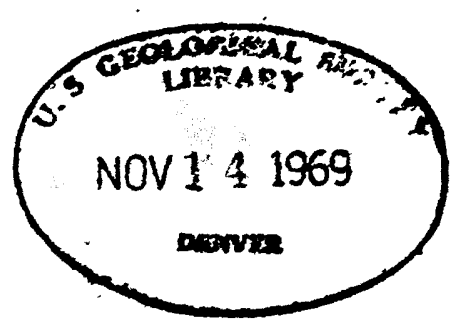

\footnotetext{
Program Number: $\quad$ W8250

Sponsor:

Equipment:

Milliam H. Chapman

IBM 360/65

Operating System: IBM System 360

Language:

Fortran IV (H-LEVEE)

Open F1le Report

$69 \cdot 10$
} 


\section{CONTENTS}

\section{Page}

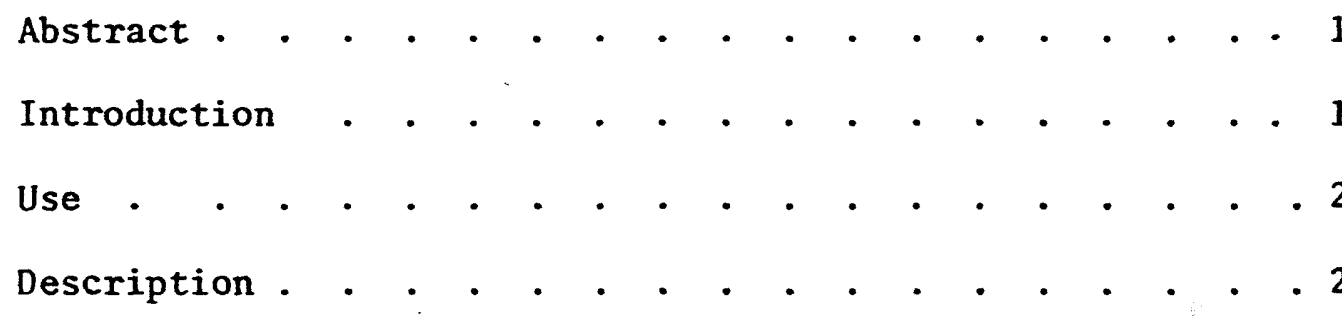

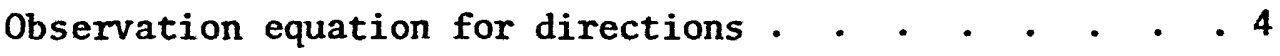

Observation equation for astronomic azimuths . . . . 5

Observation equation for lengths . . . . . . . 6

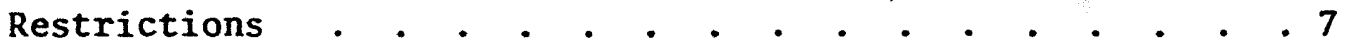

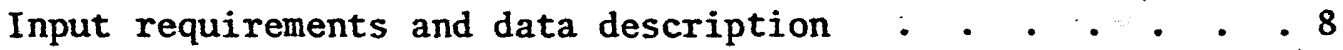

Program run preparation . . . . . . . . . . . . . 13

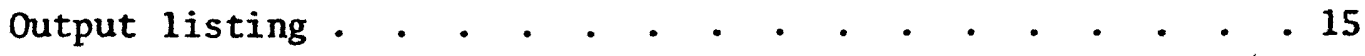

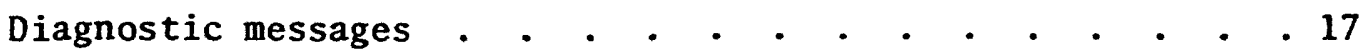

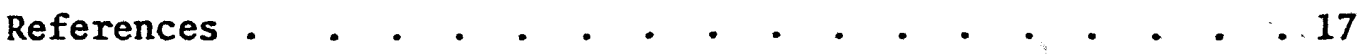

Attachments

A. Example run (input and output listings) . . . . . 19

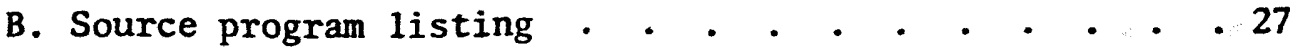




\title{
WEIGHTED TRIANGULATION ADJUSTMENT
}

by Walter L. Anderson

\begin{abstract}
The variation of coordinates method is employed to perform a weighted least squares adjustment of horizontal survey networks. Geodetic coordinates are required for each fixed and adjustable station. A preliminary inverse geodetic position computation is made for each observed line. Weights associated with each observed equation for direction, azimuth, and distance are applied in the formation of the normal equations in the least squares adjustment. The number of normal equations that may be solved is twice the number of new stations and less than 150.. When the normal equations are solved, shifts are produced at adjustable stations. Previously computed correction factors are applied to the shifts and a most probable geodetic position is found for each adjustable station. Final azimuths and distances are computed. These may be written onto magnetic tape for subsequent computation of state plane or grid coordinates. Input consists of punch cards containing project identification, program options, and position and observation information. Results listed include preliminary and final positions, residuals, observation equations, solution of the normal equations showing magnitudes of shifts, and a plot of each adjusted and fixed station. During processing, data sets containing irrecoverable errors are rejected and the type of error is listed. The computer resumes processing of additional data sets. Other conditions cause warning errors to be issued, and processing continues with the current data set.
\end{abstract}

\section{INTRODUCTION}

This program determines the most probable positions of stations in a horizontal network using the method of variation of coordinates (U. S. Geological Survey, 1966). A certain number of "fixed" station latitudes and longitudes are given along with approximate geodetic positions for "adjustable" stations as well as observed directions, azimuths, and distances between stations in the net. AlI observations are assumed to have been previously corrected for station eccentricity, swing, reduction to sea level, and so forth, and therefore must be the equivalent of sea level, 
tablet to tablet, observations. Observation equations are generated for: (1) observed directions, (2) observed astronomic azimuths, and (3) observed distances (or lengths). In addition, a selection of one of five different ellipoids may be used for the adjustment computations. A minimum of two fixed stations must be given.

This program (W8250) is a direct revision of program W5603 entitled "Triangulation Adjustment" (Anderson, 1967). Program W5603 performed a similar adjustment for unweighted observed directions. W5603 also provided for "rigid condition.equations" for astronomic azimuths and lengths. Such equations have not been included in the revised program W8250. However, a condition equation can be simulated with program $W 8250$ by using an azimuth or length-observation equation with a sufficiently large weight (e.g., w=999999999.0; see p. 12 below).

The card input to 68250 is a slight modification of the input to W5603 in order to accommodate the weight values. If the observation weight is omitted, a value of 1.0 is assumed. Therefore, W5603 data cards (with blank or zero weights) may be used directly by this program. The weighted triangulation adjustment program evolved from a need to combine different kinds of measurements (direction, azimuth, and distance) in an adjustment and to control the influences of each observation by the application of an appropriate weight.

USE

This program is primarily intended to perform the final geodetic position adjustment in a survey net used in topographic mapping. The program may also be used to find errors and blunders in the input data caused when certain program tolerances are exceeded. Various tolerances and other parameter options make the program adaptable to many survey areas and field situations.

\section{DESCRIPTION}

A latitude $\phi$ and a longitude $\lambda$ are required for every station in the triangulation net. For ease of identification a number is assigned to each station. New or adjustable stations are numbered $1,2, \ldots, N S$, where NS is the number of new stations. Fixed stations are numbered NS $+1, N S+2, \ldots$, NTS, where NTS is the total number of stations, both fixed and adjustable. 
Assuming all NTS stations latitudes and longitudes are known, the following correction factors $M$ and $P$ (in seconds) are computed and stored for later use in computing all adjustable latitudes and longitudes:

$$
M=\rho / R, \quad P=\frac{\rho}{N \cos \phi}
$$

where $\rho=206264.8062470964$,

$\mathrm{R}=$ radius of curvature in the meridian of the selected ellipsoid at the latitude $\phi$, $\mathrm{N}=$ radius of curvature in the prime vertical at $\phi$,

and $N \cos \phi=$ radius of the corresponding latitude parallel.

Then

$$
R=\frac{a\left(1-e^{2}\right)}{\left(1-e^{2} \sin ^{2} \phi\right)^{3 / 2}}, \quad N=\frac{a}{\left(1-e^{2} \sin ^{2} \phi\right)^{1 / 2}}
$$

where $e^{2}=$ square of eccentricity of the ellipsoid $=\left(a^{2}-b^{2}\right) / a^{2}$, $a=$ semimajor axis of the ellipsoid,

and $\quad b=s e m i m i n o r$ axis of the ellipsoid.

The ellipsoid is defined by the value of the parameter ISPHER from the following table (Chapman, 1967):

ISPHER Ellipsoid

$0 \quad$ Clarke 1866

1 Clarke 1880

2 Besse1

3 Everest

41) International
Semimajor axis (a) (meters)

$6,378,206.4$

$6,378,249$

$6,377,397$

$6,377,276$

$6,378,388$
Semiminor axis (b) (meters)

$6,356,583.8$

$6,356,515$

$6,356,079$

$6,356,075$

$6,356,075$

1) Lambert and Swick (1935) 
The program uses pairs of constants $\left(a, e^{2}\right)$ for each entry in the table and the selection of the ellipsoid is determined by the value of ISPHER from the card (see Input Requirements and Data Description, p. 8).

For each line observed, a preliminary inverse geodetic position computation is made using the subroutines GEDINV and LOCAZ (Chapman, 1967). The results for given stations $\left(\phi_{b}, \lambda_{b}\right)$ and $\left(\phi_{a}, \lambda_{a}\right)$ are denoted by

$$
\begin{aligned}
& \alpha_{\mathrm{ba}}=\text { forward azimuth (seconds), } \\
& \alpha_{\mathrm{ab}}=\text { back azimuth (seconds), }
\end{aligned}
$$

and, s=distance (feet).

The three types of weighted observation equations are described next. It should be noted that each type of observation equation (distance, azimuth, or length) has an associated weight (w) value which is supplied along with the observation given. The weight value is assumed to be unity (1.0) if not known (see p. 12). The weight $w$ is applied in the formation of the normal equations in the least squares process (Hildebrand, 1956).

\section{Observation Equation For Directions}

For each line associated with an observed direction and a given reorientation $z$-number (defined below), the observation equation, with given weight $w$, has the form

$$
\begin{gathered}
v=C_{\alpha}+(A-0)+z, \\
C_{\alpha}=\frac{\rho}{10 s}\left(S_{a} \sin \alpha_{a b}+E_{a} \cos \alpha_{a b}+S_{b} \sin \alpha b a+E_{b} \cos \alpha_{b a}\right)
\end{gathered}
$$

where $v=$ residual (seconds),

$\mathrm{C}_{\alpha}=$ change in direction of line (seconds),

A- $0=$ assumed minus observed direction (seconds),

$\mathrm{z}=$ reorientation term,

$s=$ computed length of line (feet),

$\alpha_{\mathrm{ba}}, \alpha_{\mathrm{ab}}=$ computed forward and back azimuths,

$\mathrm{S}_{\mathrm{a}}, \mathrm{E}_{\mathrm{a}}=$ shifts to be determined for station $A$, in southerly and easterly directions, respectively,

and

$\mathrm{S}_{\mathrm{b}}, \mathrm{E}_{\mathrm{b}}=$ shifts to be determined for station $\mathrm{B}$.

(A11 shifts $S_{a}, E_{a}, S_{b}, E_{b}$ are in units of decifeet.) 
The symbol $\mathrm{z}$ has four related uses in this paper:

1. "z-number" is the consecutive number used in the input list to identify each group of observed directions.

2. "z-equation" is the fictitious observation equation used to determine reorientation.

3. "z-value" is the actual reorientation, in seconds, as determined in the adjustment and appearing in the output listing.

4. "z-term" is the actual $z$ variable appearing in equation (3).

Schreiber's method (Rainsford, 1957, p. 175-178) is used to eliminate the normal equations associated with the $z$ or reorientation terms. This method reduces the number of normal equations that would be required if $z$-terms were included directly. The algorithm is performed while weighted observation equations (3) are being formed for any one $z$-number, where sums of corresponding weighted terms are being accumulated. These sums when multiplied through by i $\sqrt{n}$ ( $n=$ number of lines associated with a given $z$-number and $i=\sqrt{-1)}$ represent the coefficients of a fictitious observation equation (z-equation) which may be treated exactly as other observation equations while the normal equations are being formed.

Schreiber's method is slightly modified to handle a weighted $z$-equation in which the weight function can be shown to be

$$
w_{n+1}=f(w)=\frac{n}{\sum_{1}^{n} w_{i}}
$$

where $n$ is as defined above and where the $w_{i}$ are the associated weights for $i=1,2, \ldots, n \geq 2$.

Observation Equation for Astronomic Azimuths

For observed astronomic azimuths, the observation equation, with given weight $w$, has the form

$$
v=C_{\alpha}+(A-0)
$$


The term $C_{\alpha}$ is defined by (4), A-0 is the assumed minus the observed azimuth, and $v$ is the residual in seconds. Note the absence of the z-term in equation (6) in contrast to the observed direction equation (3). This absence will be noted in the results, the actual reorientation $z$-value being identically equal to zero $(0.0)$.

Observation Equation for Lengths

For observed lengths, the observation equation, with given weight $w$, has the form

$$
\begin{gathered}
v=C_{s}+10\left(A^{\prime}-0^{\prime}\right) \\
C_{s}=-S_{a} \cos \alpha_{a b}+E_{a} \sin \alpha_{a b}-S_{b} \cos \alpha_{b a}+E_{b} \sin \alpha_{b a}
\end{gathered}
$$

where v=residual (decifeet),

$\mathrm{C}_{\mathrm{S}}=$ change in length of line (decifeet), $A^{\prime}-0^{\prime}=$ assumed minus observed length (feet),

and $S_{a}, E_{a}, S_{b}, E_{b}=$ shifts to be determined for stations $A$ and $B$ in southerly and easterly directions, respectively (units in decifeet).

Normal equations are formed by the method of least squares (Adams, 1915) using the weighted observation equations (3) and (7). This wel1known technique can be found in many references (e.g., Hildebrand, 1956). The resulting normal equations become a real symmetric matrix of order 2NS, where the total number of observations must exceed this order, and -NS is the number of new stations.

The symmetric normal equation matrix is stored in vector fashion by eliminating the symmetrical elements below the main diagonal. The normal equation system with $a_{j i}=a_{i j}$ is

$$
\begin{gathered}
a_{11} x_{1}+a_{12} x_{2}+\ldots+a_{1 n} x_{n}+b_{1}=0 \\
a_{21} x_{1}+a_{22} x_{2}+\ldots+a_{2 n} x_{n}+b_{2}=0 \\
\vdots \\
\cdot \\
a_{n 1} x_{1}+a_{n 2} x_{2}+\ldots+a_{n n} x_{n}+b_{n}=0 .
\end{gathered}
$$


The coefficients are then stored in a vector in the form $a_{11}, a_{12}, \ldots$, $a_{1 n}, b_{1}, a_{22}, \ldots, a_{2 n}, b_{2}, \ldots, a_{n n}, b_{n}$. The constants $b_{i}$ may be regarded as $a_{i, n+1}$. The number of unknowns is $n=2 N S$ where $N S \leq 75$ and is the number of new stations. The solution of the normal equations (9) produces the shifts (S's and E's) for all adjustable stations. These shifts are then converted to give corrections of latitude and longitude in seconds,

$$
\Delta \phi^{\prime \prime}=-\mathrm{S} \frac{\mathrm{M}}{10}, \quad \Delta \lambda^{\prime \prime}=\mathrm{E} \frac{\mathrm{P}}{10}
$$

where $M$ and $P$ were computed previously from equations (1) and (2).

The most probable geodetic positions are now found by applying the corrections (10) to all adjustable stations. Final azimuths and distances. are computed from the inverse geodetic position subroutine GEDINV. These final station positions along with the fixed stations may be written on magnetic tape to be used later as input to the grid coordinates program (Buehrer, 1967) for state plane or grid coordinates calculations (see ZONE option, p. 9).

The probable error (p.e.) of an observation of weight unity is computed by the formula

$$
p \cdot e .=0.67449\left(\sum_{\frac{i=1}{N-(2 N S+N Z)}}^{N} w_{i} v_{i}{ }^{1 / 2}\right.
$$

where $\mathrm{N}=$ total observations, w=weight of an observation, $v=$ the residual, NS=new stations, and $\quad \mathrm{NZ}=\mathrm{z}$ 's used.

The expression (2NS+NZ) represents the total number of independent unknowns.

\section{RESTRICTIONS}

The main restriction is the number of normal equations that may be solved simultaneously. This number is twice the number of new stations and may not exceed 150. The appropriate dimension statements in the FORTRAN program could be increased perhaps to 200 , but an arbitrary limit of 150 was chosen because this should satisfy most standard nets. 
Latitudes may not exceed $90^{\circ} \mathrm{N}$. or $90^{\circ} \mathrm{S}$. and longitudes may not exceed $180^{\circ} \mathrm{E}$. or $180^{\circ} \mathrm{W}$. Directions or azimuths are always measured clockwise from south and are given to the nearest thousandth of a second in degrees, minutes, and seconds; they may never exceed $359^{\circ} 59^{\prime}$ 59.999".

\section{INPUT REQUIREMENTS AND DATA DESCRIPTION}

Data for triangulation adjustment using the USGS Computing System (IBM System 360/65) may be presented on any 80-column general-purpose data form as long as card-column requirements are followed as described below.

In preparation for the adjustment all new (adjustable) stations are to be assigned sequential numerical values, beginning with 001 . A maximum of 75 new stations can be adjusted by this program. Stations to be held fixed in the adjustment must be assigned sequential numbers immediately following those of the new stations. The total number of stations, fixed and new, must not exceed 200. Final positions will be computed for all new stations by using preliminary (approximate) positions on input.

For each occupied station, the list of observed directions, oriented approximately to true south, must be corrected for any station eccentricity existing at the time of observation. At each station, one or more znumbers (station reorientation) may be used according to field conditions. Usually one z-number is needed at each occupied station and at least two lines must be sighted from this station.

\section{Card Formats}

Each 80-column card must be properly punched according to the following instructions. On each card, column 80 is reserved for the card type identification. There are four types of cards in each data set:

Column 80

1

2

3

4
Type of Card

Header ( 1 needed)

Parameter ( 1 needed)

Position (as needed)

Observation (as needed) 
Columns Format $\quad$ Description

Header Card

\begin{tabular}{|c|c|c|}
\hline $1-62$ & $\begin{array}{l}15 \mathrm{~A} 4, \\
\mathrm{~A} 2\end{array}$ & $\begin{array}{l}\text { Project identification. May include any } \\
\text { alphabetic and (or) numeric characters. }\end{array}$ \\
\hline $63-66$ & I4 & $\begin{array}{l}\text { ZONE (1) option. If final grid coordinates } \\
\text { are desired for all stations, record the } \\
\text { proper zone number as defined in Buehrer } \\
\text { (1967). When ZONE (1) is not zero, the } \\
\text { program will write all final positions } \\
\text { on tape for subsequent processing by the } \\
\text { grid coordinates program. Where ZONE (1) } \\
\text { is zero (or blank), this option is not } \\
\text { selected and ZONE (2),.., ZONE (4) below } \\
\text { are irrelevant. }\end{array}$ \\
\hline $67-70$ & I4 & $\begin{array}{l}\text { ZONE (2). May be selected only if ZONE (1) } \\
\text { is non-zero. }\end{array}$ \\
\hline $71-74$ & I4 & ZONE (3). Same as ZONE (2). \\
\hline $75-78$ & I4 & ZONE (4). Same as ZONE (2). \\
\hline 80 & I1 & Must be "1". \\
\hline
\end{tabular}

Parameter Card

The total number of stations (NTS) in columns 3-5 must be at least two greater than the number of new stations (NS) in columns 1-2; i.e., at least two stations must be held fixed.

If length or azimuth tolerance is exceeded in absolute value, the program rejects the observation equation and terminates after all observations have been read; no adjustment will be provided for rejected lines because such rejection would probably indicate a data error and the results would be invalid. If observations are rejected, the program will print all observation equations with appropriate messages to aid the user in identifying sources of error (see Diagnostic Messages, p. 17).
1-2
12
Number of new stations NS $(1 \leq \mathrm{NS} \leq 75)$.
3-5 I3
Total number of stations NTS (NS $<$ NTS $<200$ ). Note: NTS must be greater than NS. Thus the number of fixed stations in the net is NTS minus NS. 
$6-8$

13

$9-12$

14

$27-31$

F5. 2

$32-37$

F6. 3

80

$N Z=l$ as $\dot{t} z$-number used.

ISPHER=type of ellipsoid selected. Use

ISPHER =0 (or blank) for Clarke 1866

ISPHER $=1$ for Clarke 1880 ,

ISPHER $=2$ for Bessel

ISPHER $=3$ for Everest,

ISPHER $=4$ for International.

ISPHER $>4$ will be used as though ISPHER $=0$.

Length tolerance (maximum allowable absolute difference between observed and computedlengths (times 10.0) in the assumed figure-required in testing length observations equations, if any) scaled to $x x x . x x$ decifeet. If no length tolerance is specified, then the program automatically allows a default tolerance of 250.00 decifeet. When recording a number with two decimal places, the decimal point need not be punched; however, the decimal point may be punched anywhere in the field 27-31. Therefore, numbers as large as 9999. may be used by punching the decimal point in column 31 .

Azimuth tolerance (maximum allowable absolute difference between observed and computed azimuths in the assumed figure-- required in testing all observation equations and azimuth observation equations) scaled to $x x x . x x x$ seconds. If no azimuth tolerance is specified, then a default value of 60.000 seconds is assumed by the program. Numbers as large as 99999 . may be used by overriding the assumed decimal position.

Must be "2".

\section{Position Card}

If more than one station is on a card, the additional (if any) station(s) must be consecutive with respect to the first station number. The order of position cards is irrelevant as long as all stations are recorded with the general convention that new stations be numbered consecutively from 1 to NS and that fixed stations be numbered consecutively from NS+1 to NTS. Any number of position cards may be included until all NTS stations are recorded. 


\begin{tabular}{|c|c|c|}
\hline $4-6$ & 13 & First station number on this card. \\
\hline $7-9$ & 13 & Last station number on this card. \\
\hline $10-20$ & $\begin{array}{l}\mathrm{Al}, \\
2 \mathrm{I} 2, \\
\mathrm{~F} 6.4\end{array}$ & $\begin{array}{l}\text { Latitude of first station in the form } \\
\text { +DDMMSS.SSSS. }\end{array}$ \\
\hline $21-32$ & $\begin{array}{l}\text { A1, } \\
\text { I3, } \\
\text { I2, } \\
\text { F6. } 4\end{array}$ & $\begin{array}{l}\text { Longitude of first station in the form } \\
\text { +DDDMMSS.SSSS. }\end{array}$ \\
\hline $33-43$ & & Latitude of second station, or blank. \\
\hline $44-55$ & & Longitude of second station, or blank. \\
\hline $56-66$ & & Latitude of third station, or blank. \\
\hline $67-78$ & & Longitude of third station, or blank. \\
\hline 80 & Il & Must be "3". \\
\hline
\end{tabular}

\section{Observation Card}

One observation card is required for each observation (direction, azimuth, or length). A line observed in both directions requires two cards.

The type of observation $(A, B, C)$ is defined by the rules:
(A) Observed direction given if $z \neq 0$ ( $z$ in columns $3-5$ );
(B) Astronomic azimuth given if $z \neq 0$ and length $=0.00$ (length in columns 45-52);
(C) Length given if $z=0$ and length $\neq 0.00$.

Any and all azimuth and (or) length observations (with $z=0$ ) must be placed in the deck ahead of the $z \neq 0$ observed direction cards. The order and number of azimuth and length observation cards are arbitrary. However, the observed direction cards must be grouped and ordered consecutively by $z$-number (column 3-5) and must begin with 001 for the first group. Each z-group must have at least two observed directions per group. 
In order to perform a least squares analysis, the total number of observation cards must exceed the number of equations to be solved simultaneously. The program will count the number of observations and check this before proceeding with the solution of the normal equations.

\begin{tabular}{|c|c|c|}
\hline $3-5$ & I3 & $z$-number. \\
\hline $6-7$ & I2 & $\begin{array}{l}\text { Number of observation cards associated } \\
\text { with current } z \text {-number; required only } \\
\text { on the first card of each } z \text {-number group } \\
\text { but must be greater than } 1 \text { if } z \neq 0 \text {. }\end{array}$ \\
\hline $8-10$ & I3 & $\begin{array}{l}\text { Occupied station B; must be the same } \\
\text { for all cards with the same } z \text { (except } \\
\text { if } z=0 \text { ). }\end{array}$ \\
\hline $11-13$ & 13 & Observed station A. \\
\hline $14-23$ & $\begin{array}{l}\text { I3, } \\
\text { I2, } \\
\text { F5.3 }\end{array}$ & $\begin{array}{l}\text { (A) Observed direction } B \text { to } A \text { in the form } \\
\text { DDDMMSS.SSS. }\end{array}$ \\
\hline $24-34$ & $\begin{array}{l}\text { A1, } \\
\text { I3, } \\
\text { I2, } \\
\text { F5.3 }\end{array}$ & $\begin{array}{l}\text { (B) Observed (astronomic) azimuth of } \\
B \text { to A in the form +DDDMMS.SSS. For } \\
\text { an azimuth observation of due south, } \\
\text { record the symbol "-" or "S" in } \\
\text { column 24. }\end{array}$ \\
\hline $35-44$ & F10.5 & $\begin{array}{l}\text { Weight }(w) \text { of an observation (applies to } \\
\text { any type, } A, B \text {, or C). } w=1.0 \text { is assumed } \\
\text { if columns } 35-44 \text { are left blank or punched } \\
\text { as zero ( } 0) \text {. If the assumed decimal is } \\
\text { overridden, the largest weight that may } \\
\text { be used is } 999999999 . \text { (N.B. it will be } \\
\text { printed as } * * * * * * * * * * \text { if used). }\end{array}$ \\
\hline $45-52$ & F8. 2 & $\begin{array}{l}\text { (C) Observed length scaled to two implied } \\
\text { decimals, in feet. Leave blank (or use } \\
0.00 \text { ) if a length observation is not } \\
\text { given. }\end{array}$ \\
\hline 80 & I 1 & Must be " 4 ". \\
\hline
\end{tabular}




\section{PROGRAM RUN PREPARATION}

The following deck setup includes OS/360 control cards as well as the triangulation adjustment data deck requirements. The deck arrangement cannot be changed if the standard USGS production program on disk is being used.

The OS/360 control cards are identified by //'s in columns 1-2. Each control card must be punched on an IBM 029 keypunch or equivalent card codes must be used. The symbol " $b$ " denotes a blank card column. The deck order must be:

1. Users JOB card

2. //JOBLI BbDDbDSNAME $=$ SYS 1. LOADLIB, $\mathrm{DISP}=(\mathrm{SHR}, \mathrm{PASS}, \mathrm{KEEP})$

3. //bEXECbW8250

4. //GO.SYSINbDDb*

5. Data deck in the following order:

(a) Header card (column $80=1$ )

(b) Parameter card (column $80=2$ )

(c) Position cards (column $80=3$ ) as many as needed; in any order desired.

(d) Observation cards (column $80=4$ ) as many as needed; arranged in consecutive order with respect to the z-number (columns 3-5) groups.

(e) End-of-observation (EOB) card An EOB card is a delimiter card with columns 1-79 blank and column 80=9.

(f) Repeat steps a-e for as many independent problems as desired.

(g) End-of-data card (always required following last EOB card; the format is columns 1-80 blank or all zeros.

6. $/$ * End-of-file card. Contains $" / * "$ in columns $1-2$.

\section{Input/Output Devices}

The following devices are required:

1. Card reader/tape (SYSIN file).

2. Line printer/tape (SYSOUT file).

3. Three scratch disk files. The catalog procedure $\mathbf{W} 8250$ in step 3 above will automatically allocate the required disk space.

4. One 2400 9-track tape when the grid coordinates tape option (ZONE ( 1$) \neq 0$ ) is selected. This file is automatically setup to use USGS tape volume serial number 1008, unless otherwise overridden by including between cards 3 and 4 the control card //G̣O.FTIOFO0lb DDbVOLUME $=S E R=x x x x, x x x x$ being the particular tape number. 
The format of the grid coordinates tape is written with unblocked 80 -character $B C D$ records in the following order:

Columns

Description

a. Header record where

$1-62$

63-66

$67-70$

$71-74$

$75-78$

80
Project identification.

ZONE (1), not zero.

ZONE (2).

ZONE (3).

ZONE (4).

0 .

b. Final position records in the following form where the implied decimal in the latitude and loneitude seconds is SS.SSSS

$1-3$

$21-31$

$32-43$

80
Station number.

Lati tude in +DDMMSSSSSS .

Longitude in \pm DDDMMSSSSSS .

2 .

c. End record after last position

$1-79$

80

blanks .

6 .

d. Other grid coordinate data sets in order of a-c above.

e. End-of-file mark follows the last end record.

The "Grid Coordinates Program" (Buehrer, 1967) reads data from file FT10F001 if the data is not from cards. Instead of using a tape as permanent storage for the final positions (ZONE option), one may use a disk work file as temporary storage and obtain the grid coordinates immediately after the triangulation adjustment. The final positions are not retained on the disk work file as with tape, but retention may not be necessary.

The deck arrangement for automatically obtaining grid coordinates after adjustment is then:

1. Users JOB card

2. //JOBLI BbDDbDSNAME $=$ SYS 1. LOADLIB, $\mathrm{DISP}=(\mathrm{SHR}, \mathrm{PASS}, \mathrm{KEEP})$

3. //bEXECbW8250 
4. //GO.FT10F001bDDbUNIT $=$, LABEL $=$, VOLUME $=$, DISP $=0 L D$, DSNAME $=S Y S 1$. WORK 4

5. //GO.SYSINbDDb*

6. Data deck in order (a) - (g) above -- with ZONE option selected in desired problems

7. $/ *$

8. //bEXECbPGM=D0154, REGION=252K

9. //FT06F001bDDbSYSOUT $=\mathrm{A}$

10. //FT10F001bDDbDSNAME=SYS1. WORK 4, DISP $=$ OLD

11. //FT11F001bDDbDUMMY

12. //FT05F001bDDb*

13. $/ *$

\section{OUTPUT LISTING}

In general, the printout is presented in the following order (refer to the attached example output listing, p. 19-26):

Part 1. Preliminary positions and observation equations (p. 19-21).

Part 2. Solution of normal equations, showing magnitudes of the station shifts. Also given is the back substitution check using the solution vector in the normal equations (p. 22).

Part 3. A plot of the adjusted and fixed stations with each station identified. The plot is included mainly as a visual check showing the final data and is not intended as an accurately scaled plot ( $p .23$ ).

Part 4. Final positions and residuals (p. 24-26).

Parts 2 and 3 are of little practical importance to the user but may be useful in a detailed study of the adjustment. Parts 1 and 4 are the basic input and output data. In each, two printout lines are devoted to one field observation. In a general way, the left half of each printout refers to the station occupied (B) and the right half to the station observed (A). 
In Part 1 the first line of each pair lists the data of the assumed net in the following order:

Numerical designation of occupied station B

Preliminary LAT B, LONG B, and forward azimuth AZBA

Inversed distance between stations (denoted by $\mathrm{S}$ )

Numerical designation of observed station A

Preliminary LAT $A$, LONG $A$, and back azimuth AZAB

The second line of each pair contains observation equation coefficients and constants as follows:

The z-number associated at station $B$

The shift coefficients at B (if adjustable)

The observed direction (appears under AZBA column)

The observation weight (denoted by WT)

The shift coefficients at A.(if adjustable)

The equation constant term

Except for the $z$-number and azimuth, the coefficients are all expressed in exponential form which consists of a decimal number times a signed twodigit power of 10 (e.g., $0.12345678 \mathrm{D}-02$ represents the number 0.0012345678 , etc.).

In Part 4 (final positions and residuals) the first line of each pair has the same format as the corresponding line of Part 1: B, LAT B, LONG B, AZBA, S, A, LAT A, LONG A, AZAB. These values are based on the final geodetic positions found after applying the adjustment and inverse computations. The second line of each pair shows the shift corrections to the assumed latitude and longitude at both stations (i.e., adjustable stations). The term denoted by $V$ is the residual (or adjustment correction) for the observation; the $z$-value (station reorientation term) for the occupied station is given at the end of the line. The maximum absolute residual and probable errors are given after the final position listing ( $p .26$ ). 


\section{DIAGNOSTIC MESSAGES}

Errors detected in the header, parameter, position, or observation cards will be noted at run time and printed along with any results collected at the time the error is detected. Attempts are made to process the entire data file even if errors are discovered.

If a severe or irrecoverable error is detected in a data set on the header, parameter, or position cards, the message "DATA SET FLUSHED FROM FOLLOWING CARD" is given. The program will first flush all remaining cards until an EOB card (column 80=9) is read, and will then resume processing any subsequent data set(s). If a severe error on an observation card is encountered, the program will print the message "\$\$\$ $\$$ OBSERVATION REJECTED $\$ \$ \$ "$ and continue reading and editing all remaining observation cards. This procedure permits detection of other possible errors in the data following the first severe observation card error. After the last observation card is read, the program will print the number of rejected observations and resume processing any subsequent data set(s).

Messages will be printed upon detection of errors and will contain:

Card-type identification

Error message in detail

Card-column guide lines

Card contents

Certain warning errors will permit the program to continue with the current data set but may indicate a possible source of error. For example, the message "...MINUTES OR SECONDS.GT. 60.0" may be a result of a card-punching error. However, the program allows the minutes or seconds portion of angles to be greater than 60.0 during the processing.

\section{REFERENCES}

Adams, 0. S., 1915, Application of the theory of least squares to the adjustment of triangulation, U.S. Coast and Geodetic Survey Special Publication 28.

Anderson,-W. L., 1967, Triangulation adjustment program, Program W5603, U. S. Geological Survey Computer Program Documentation (unpublished).

Buehrer, W. A., 1967, Grid coordinate program, Program D0154, U.S. Geological Survey Computer Program Documentation (unpublished). 
Chapman, W. H., 1967, fieodetic position and inverse program, Program W5501, Office of Research and Technical Standards, U. S. Geological Survey Computer Program Documentation (unpublished).

Hildebrand, F. B., 1956, Introduction to numerical analysis, McGraw-Hill, New York,

Lambert, W. D., and Swick, C. H., 1935, Formulas and tables for the computation of geodetic positions on the International Ellipsoid, U. S. Coast and Geodetic Survey Special Publication 200.

Rainsford, H. F., 1957, Survey adjustments and least squares; Frederick Ungar Pub. Co., New York.

U. S. Geological Survey, 1966, Topographic instruction of the U. S. Geological Survey, Triangulation adjustment by variation of coordinates, Book 2, Chapter 2B7. 


\section{ATTACHMENTS}


A. EXAMPLE RUN

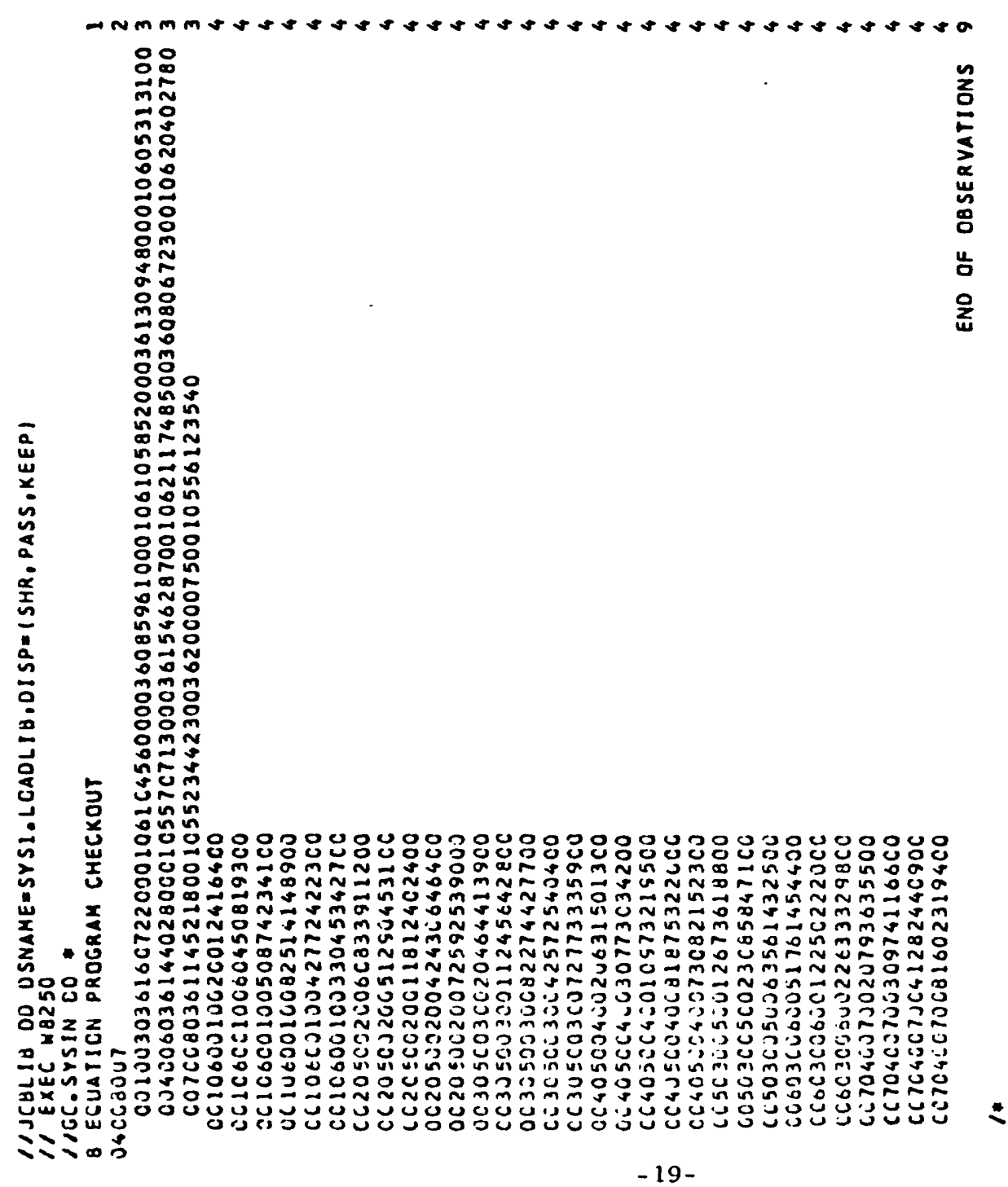




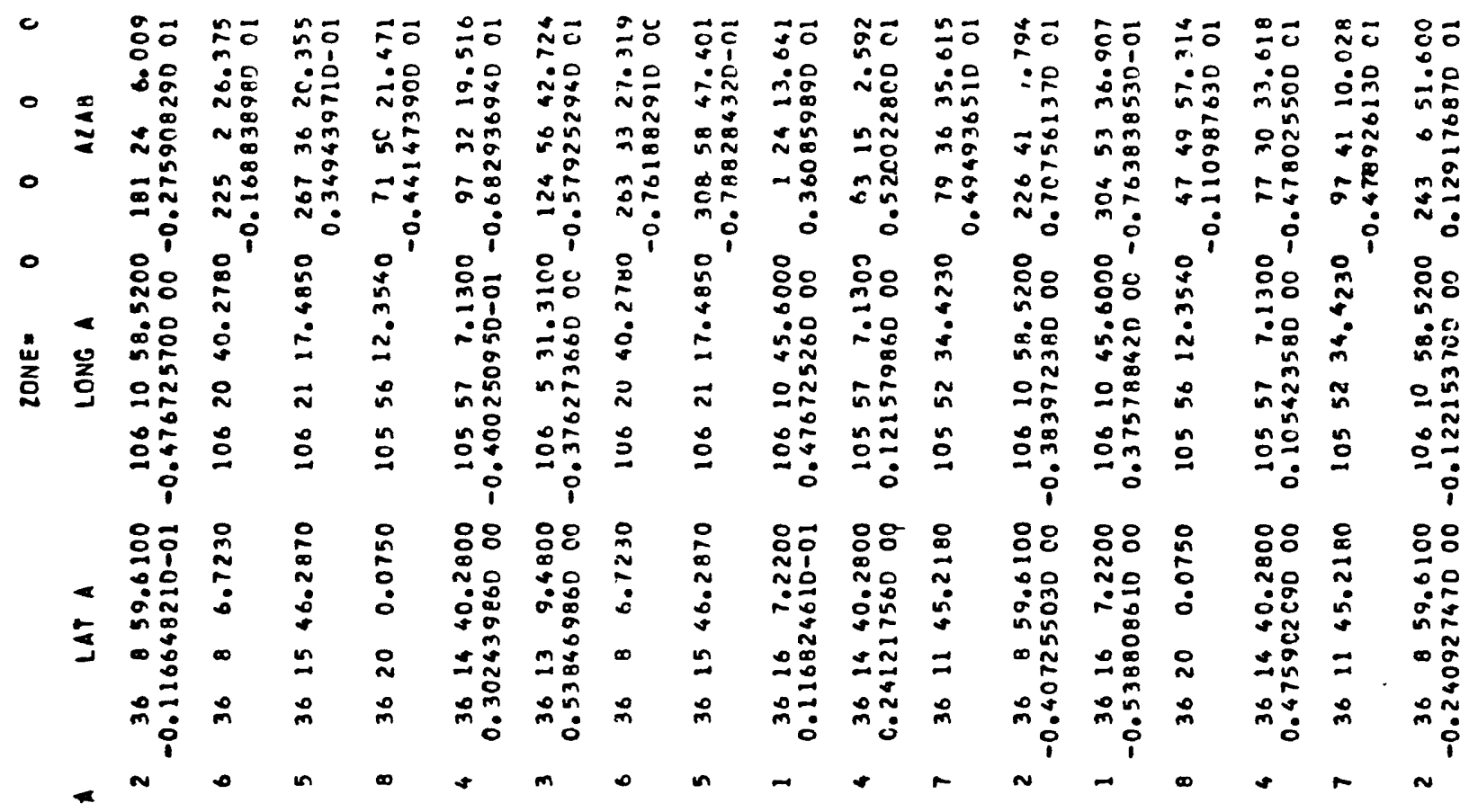

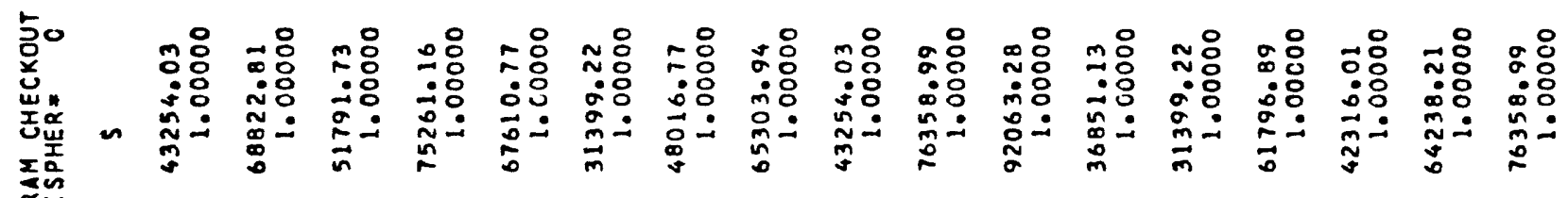

过

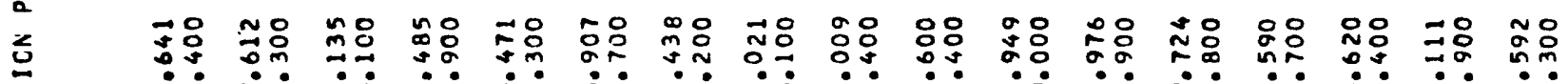
E

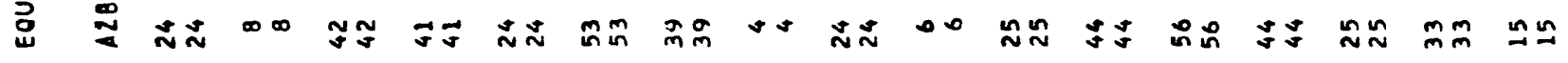

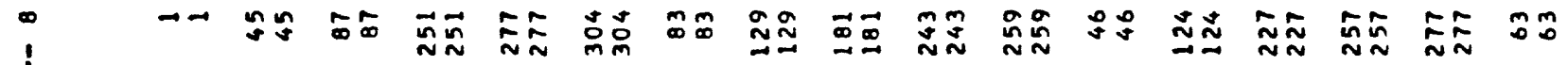

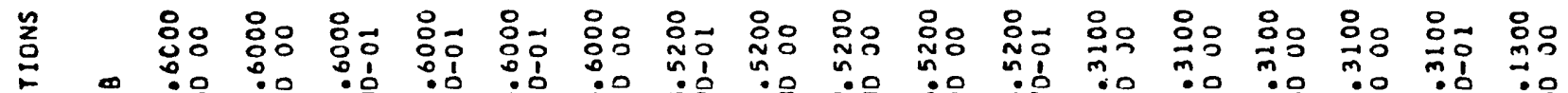

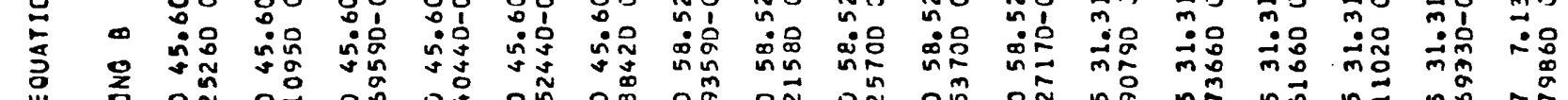

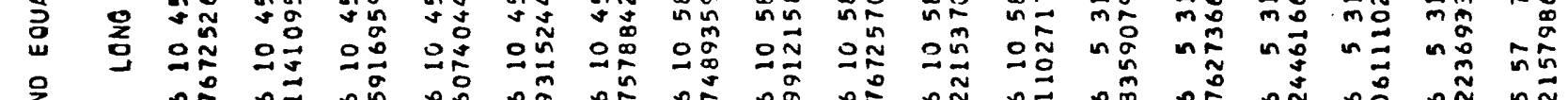

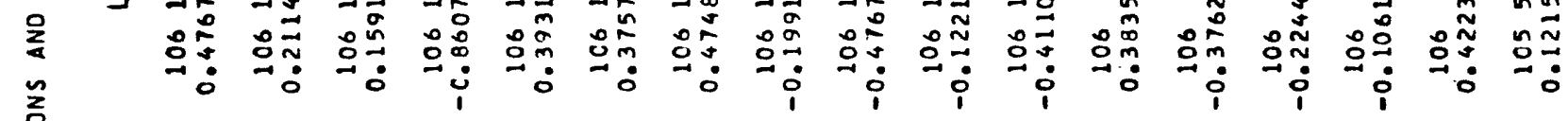

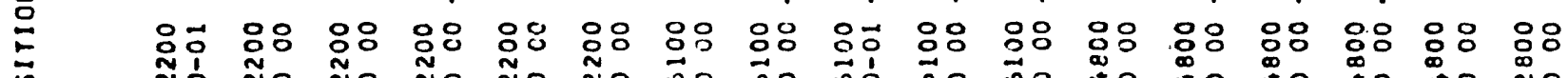

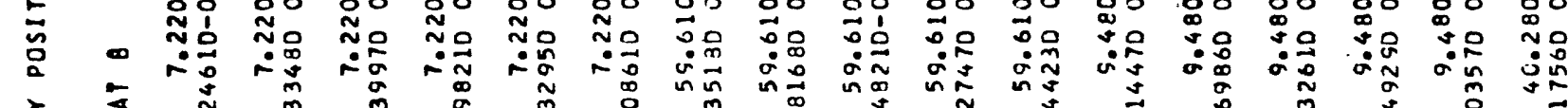

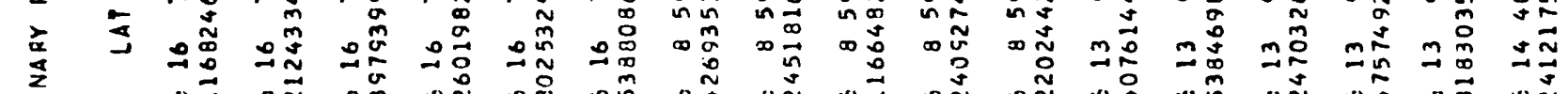
至

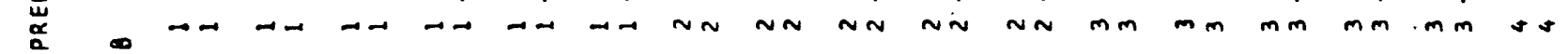




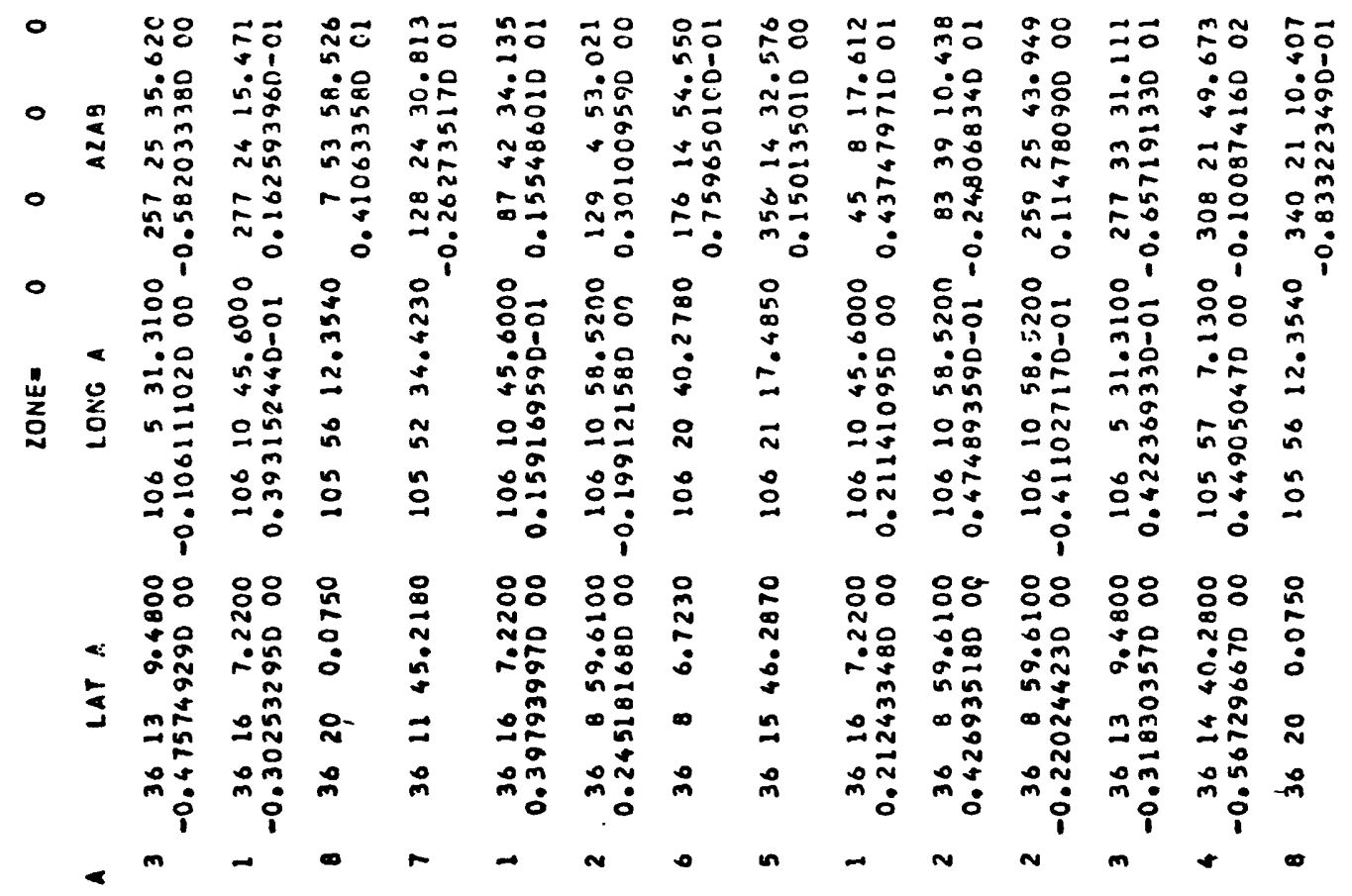

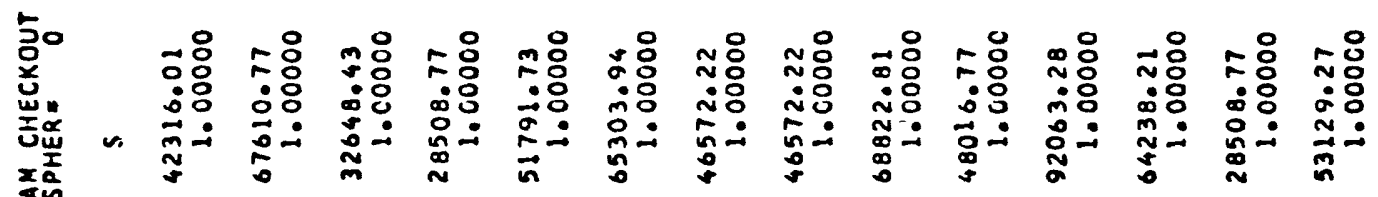

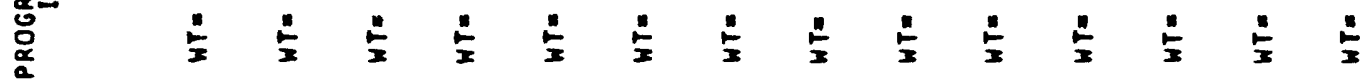

항

J

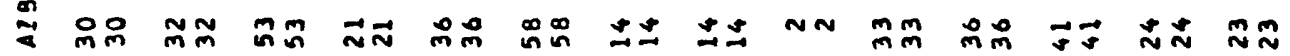

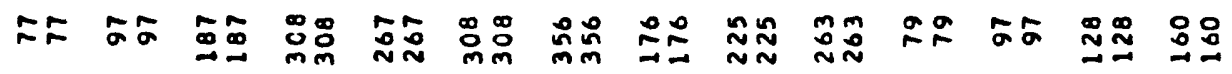

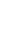

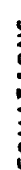

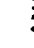

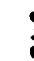

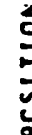

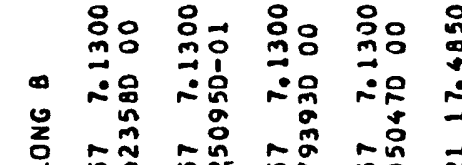

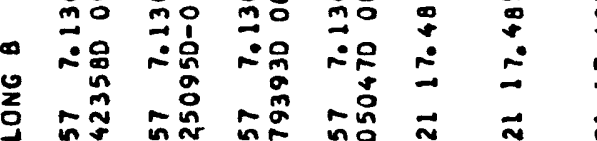



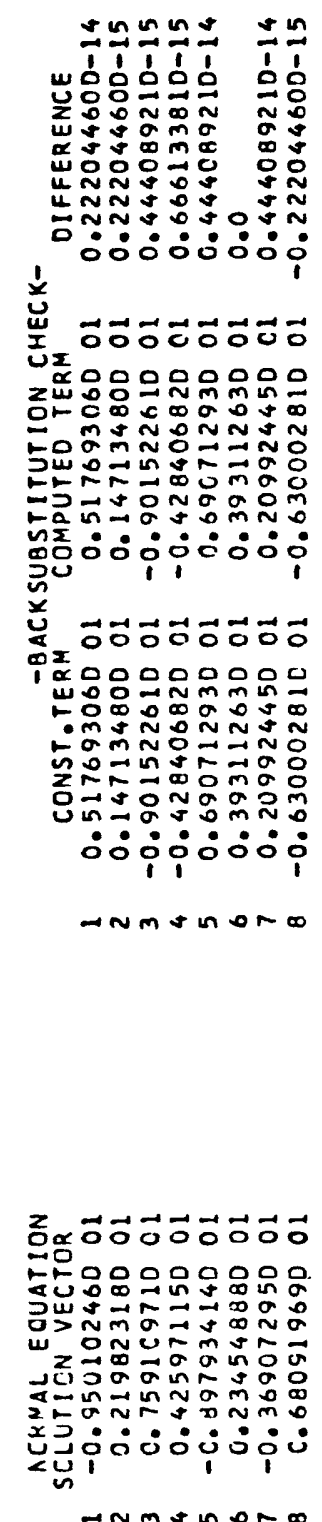


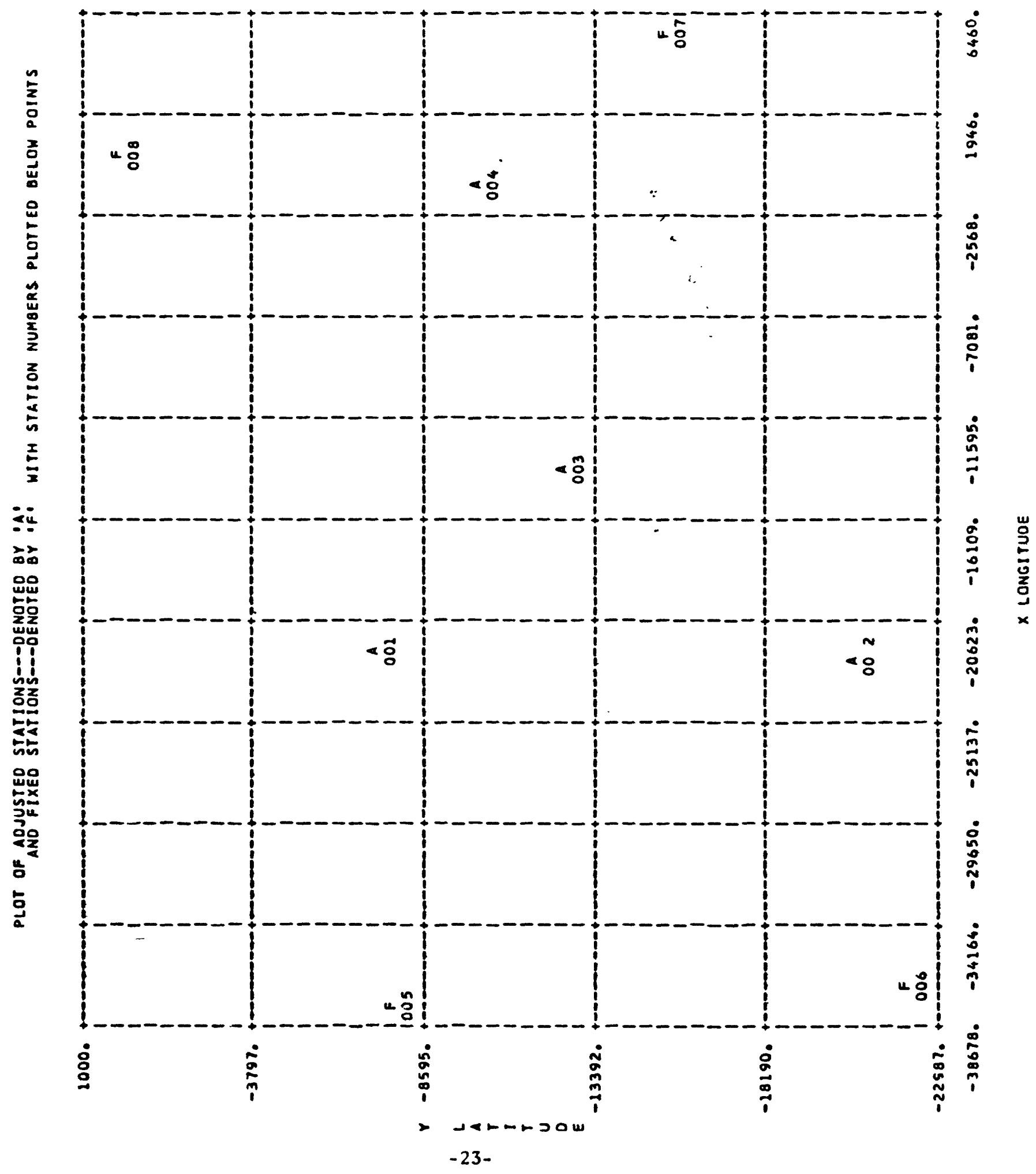




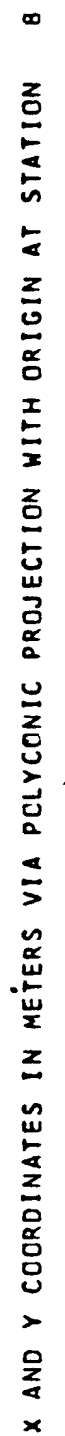

$-24-$ 


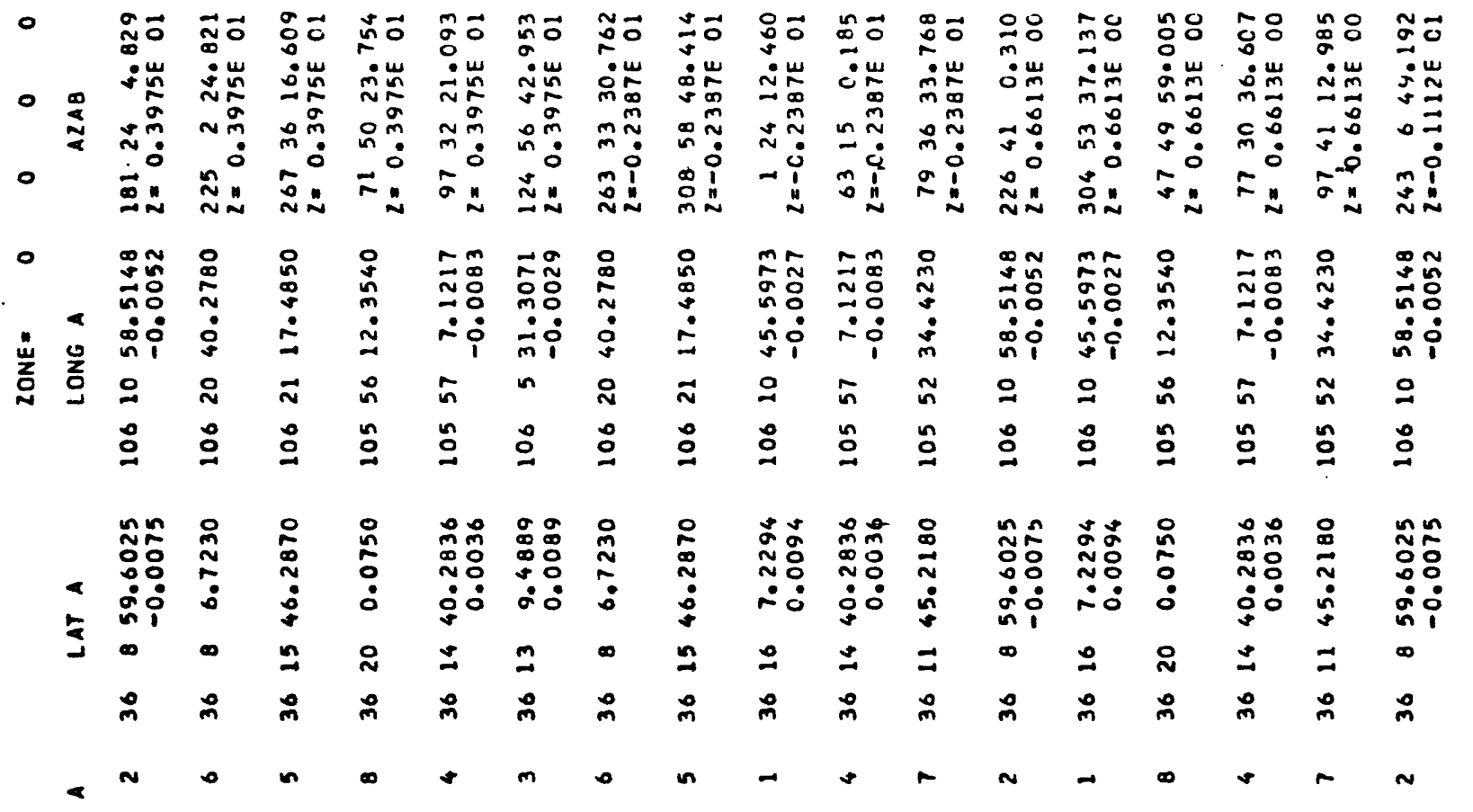

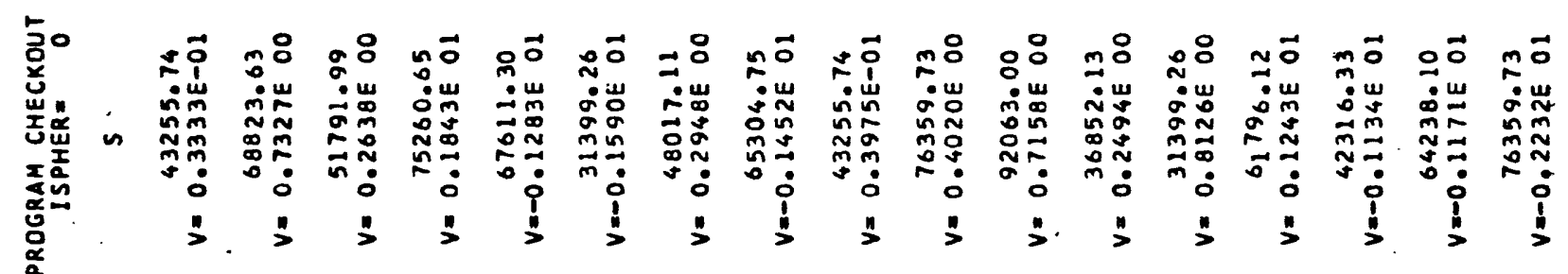

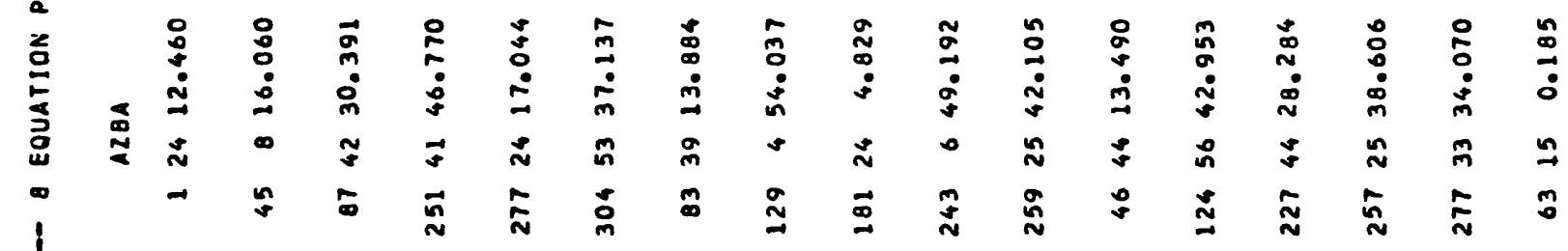

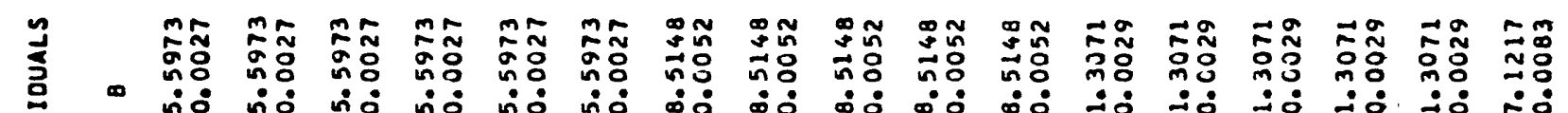
๘ जi

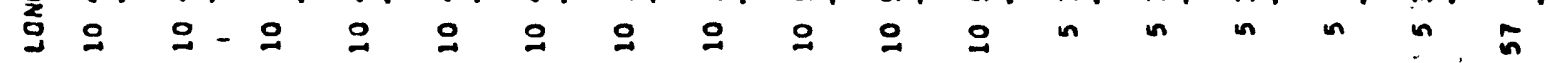

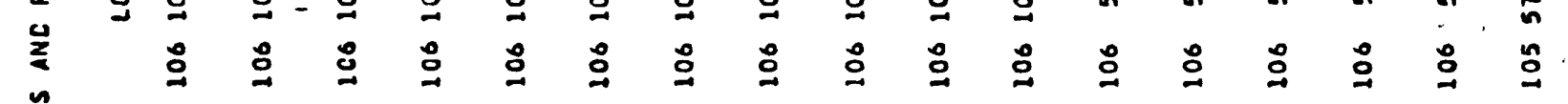

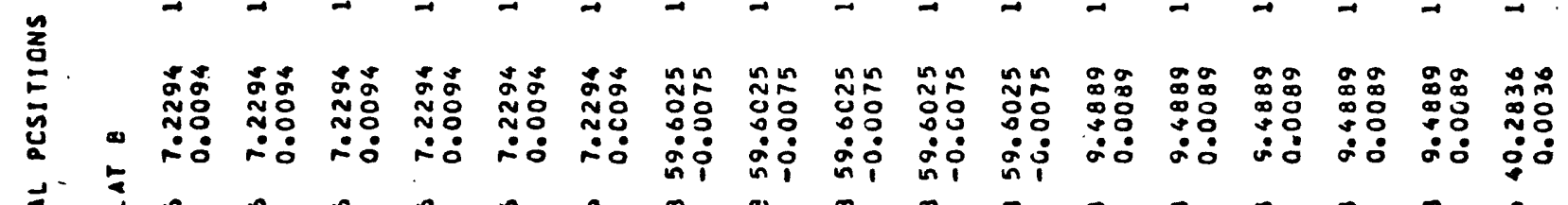

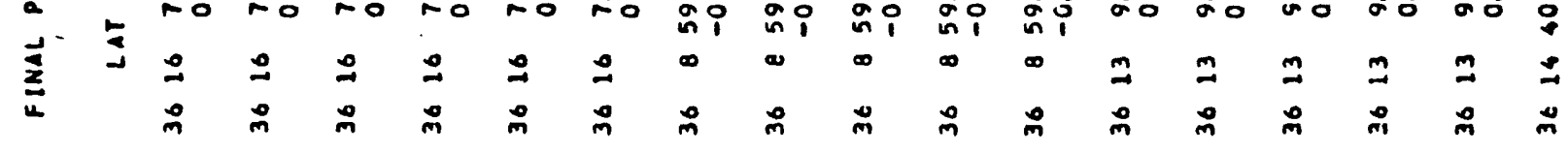


- 边 竞

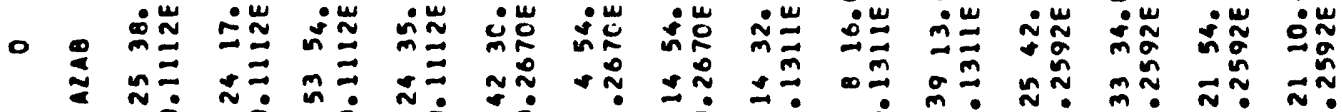
袋

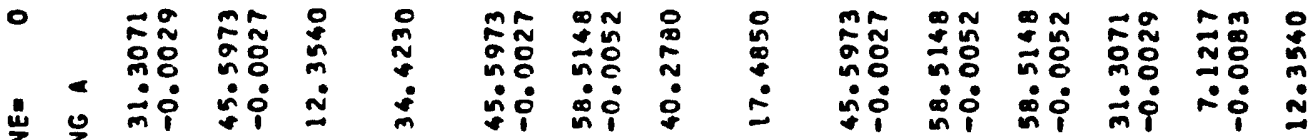

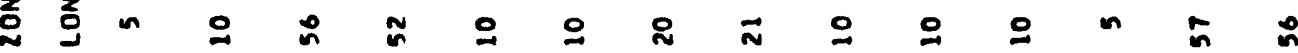

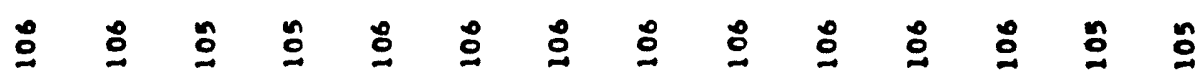

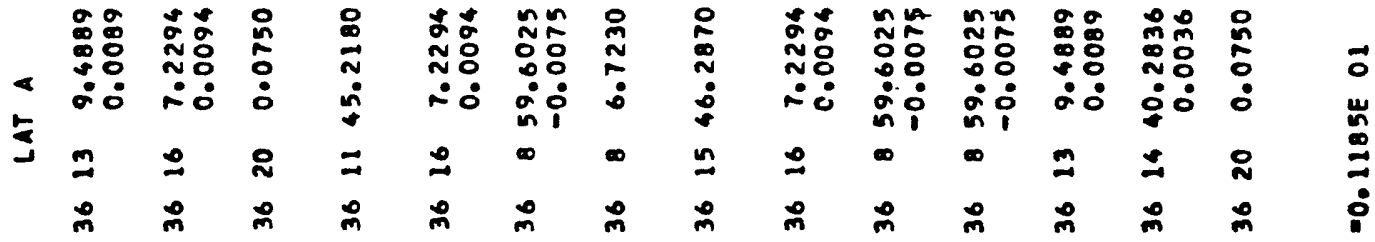

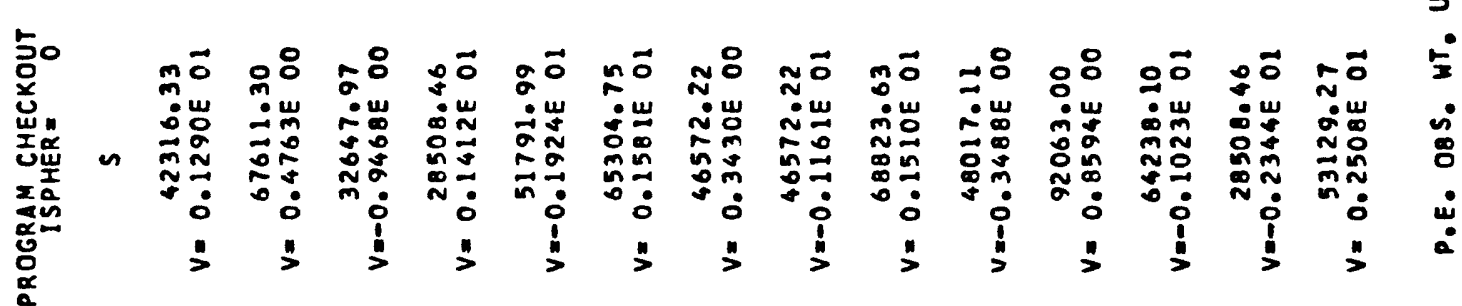

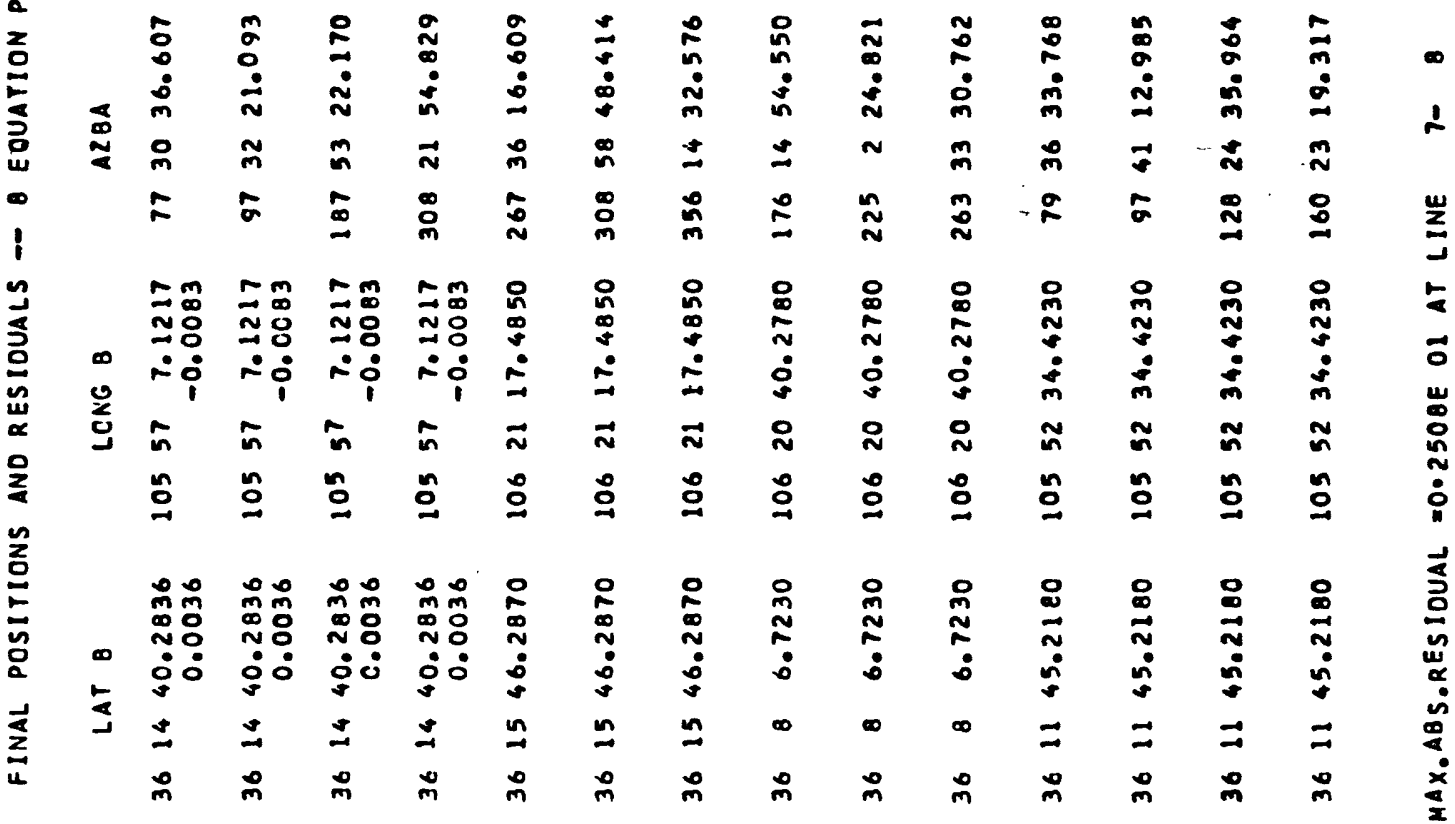
$\infty$ 
B. SOURCE PROGRAM LISTING

$\overrightarrow{8}$

岁

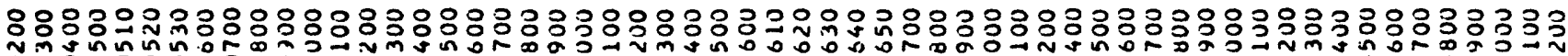

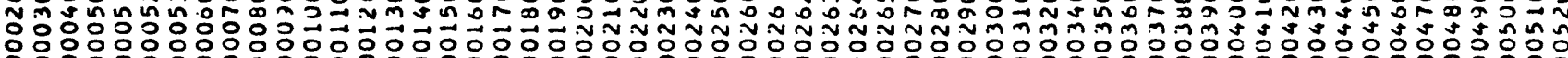

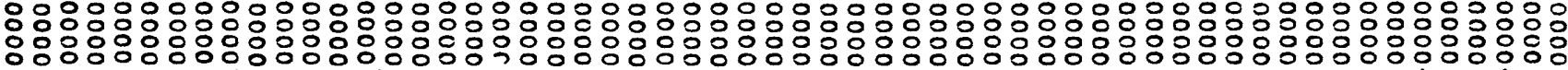
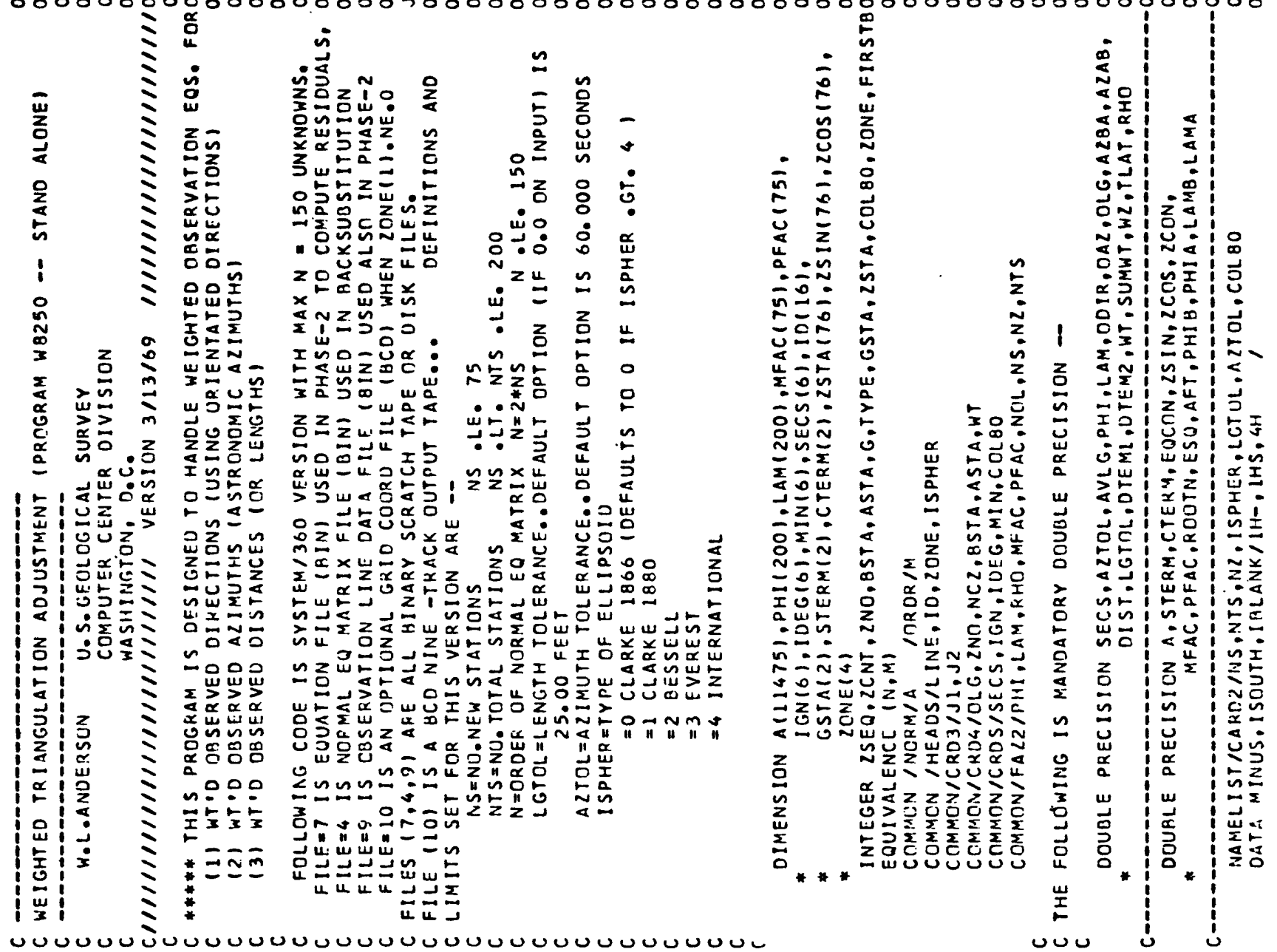

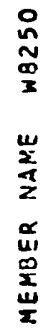




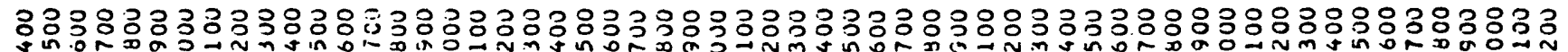

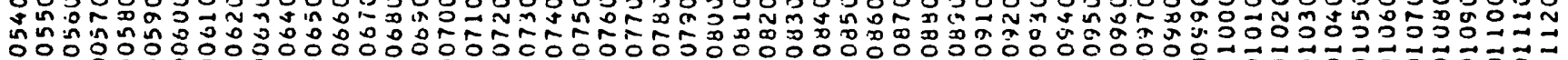

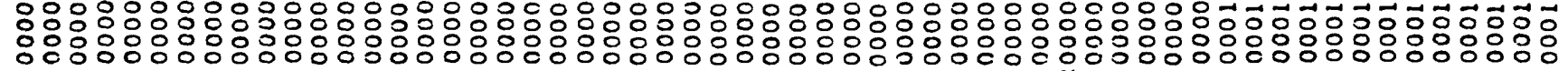

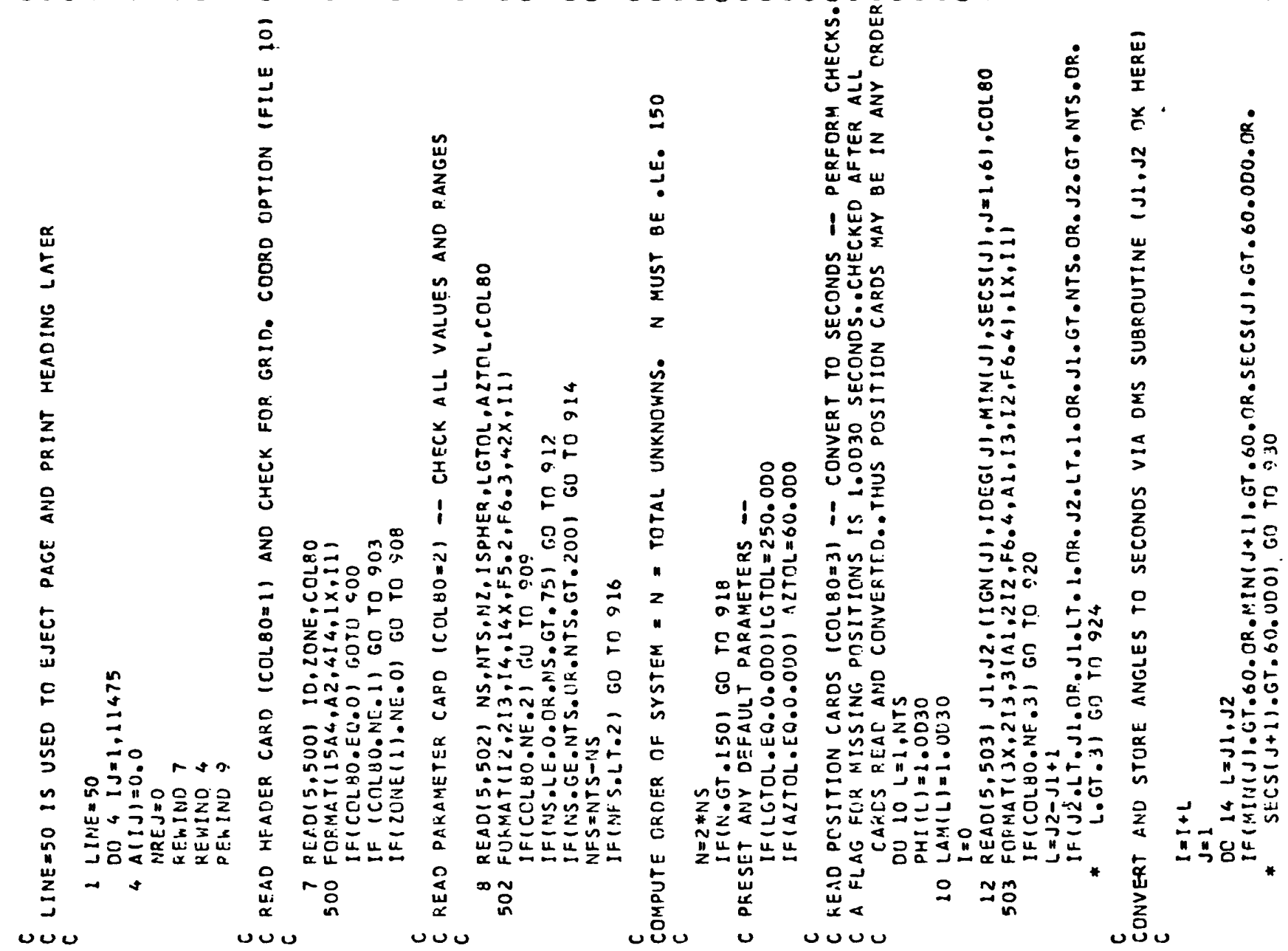




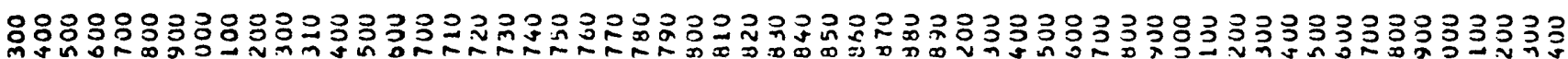

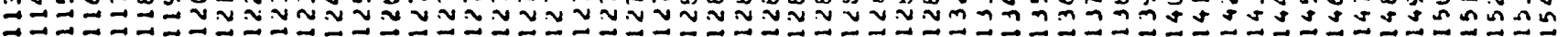

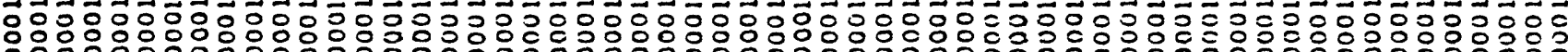

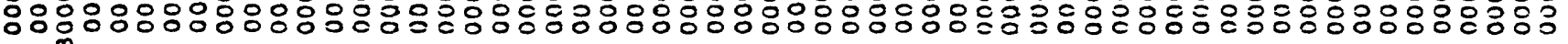

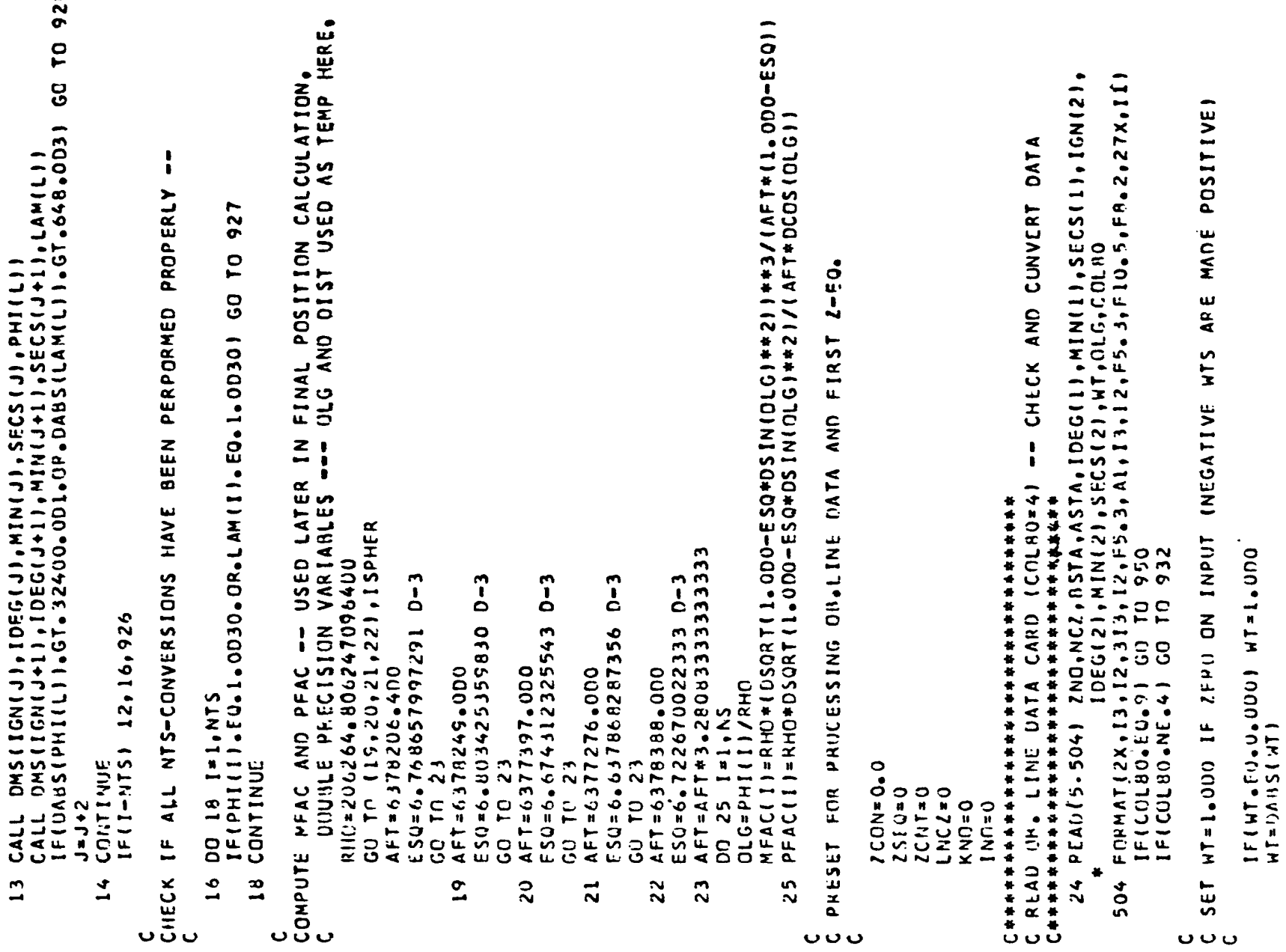

$\underset{\substack{n \\ \mathfrak{n}}}{\stackrel{N}{\mathfrak{N}}}$

$\stackrel{w}{\stackrel{2}{5}}$

嵌 


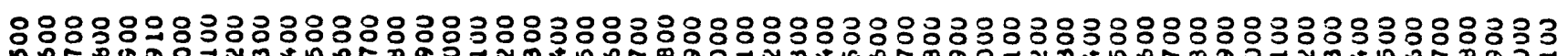
ñ匕نn

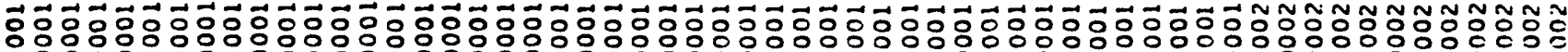

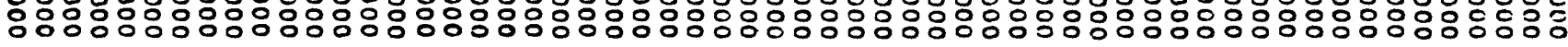

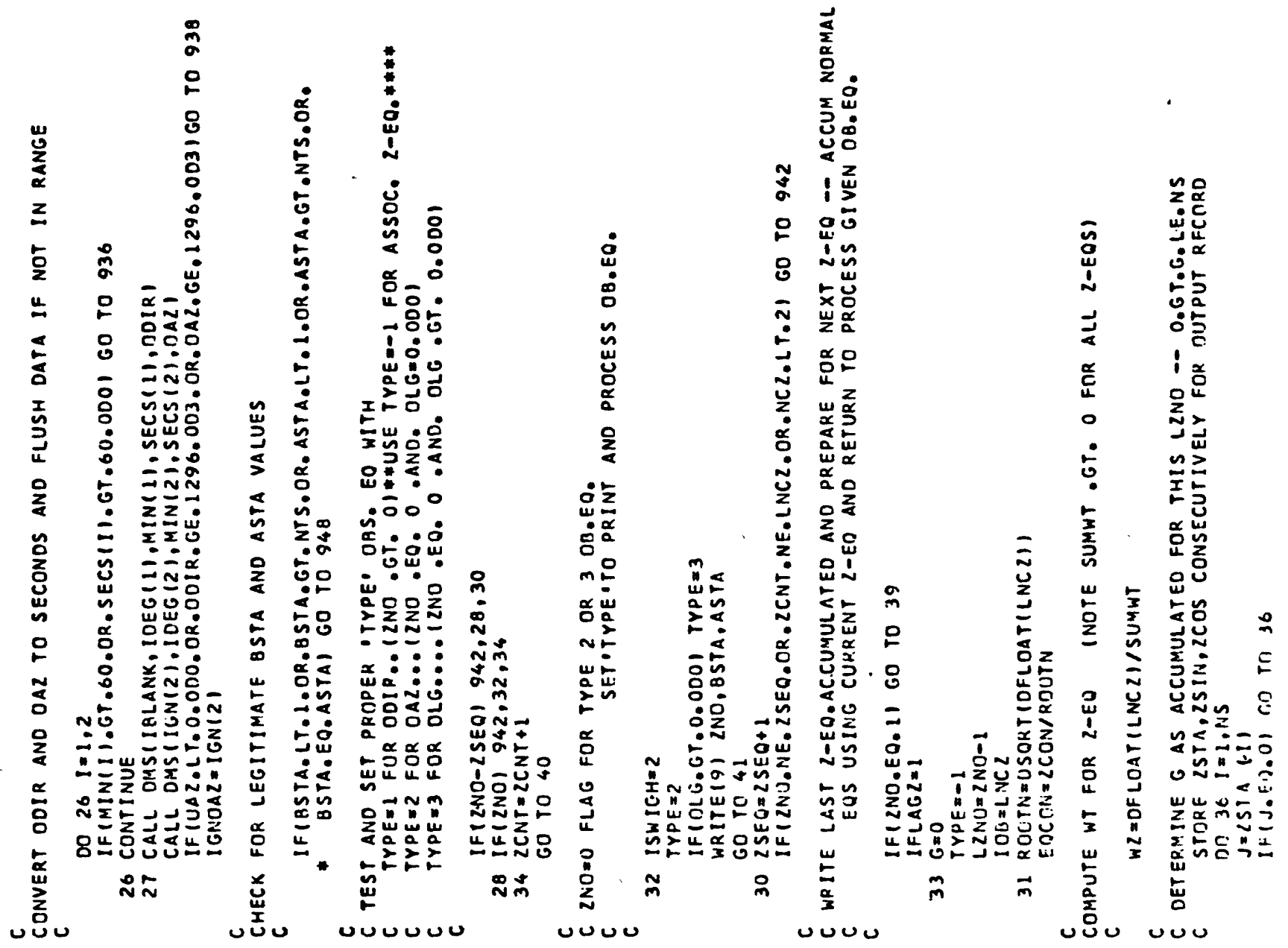




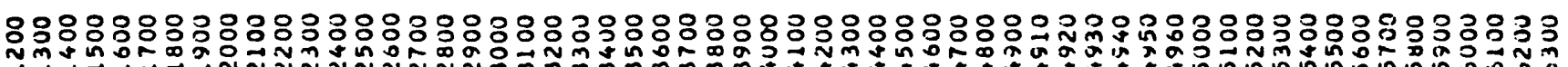

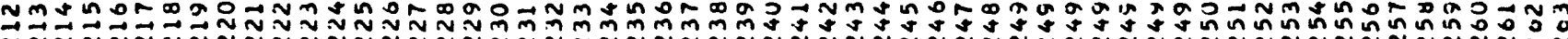

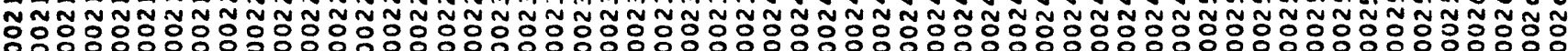

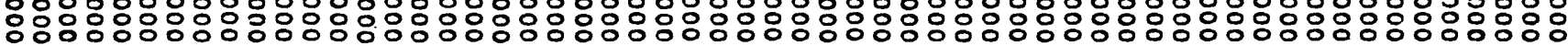

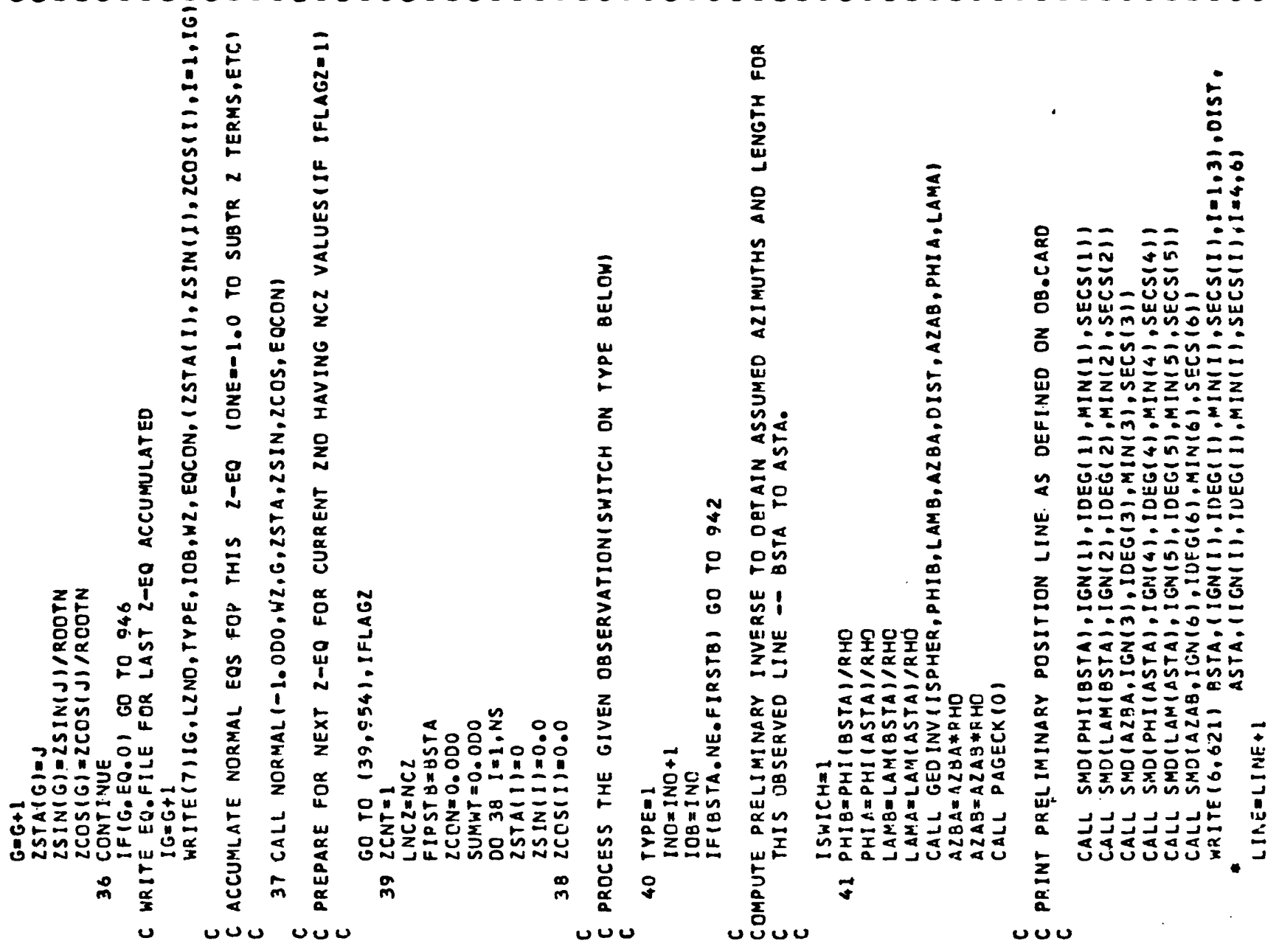

울

$\underset{\substack{\mathbf{z} \\ \mathbf{z}}}{\mathbf{m}}$

品 


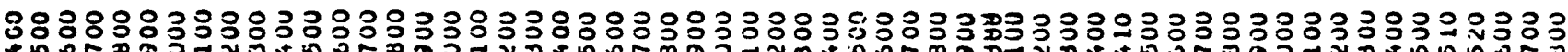

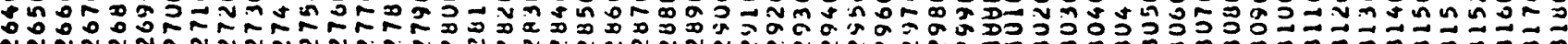

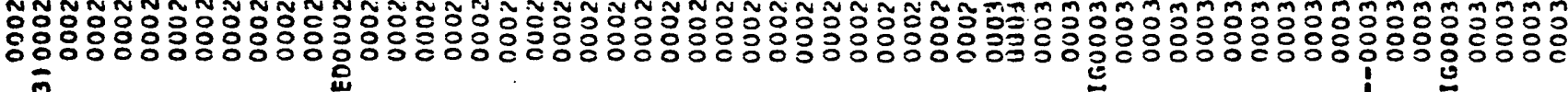
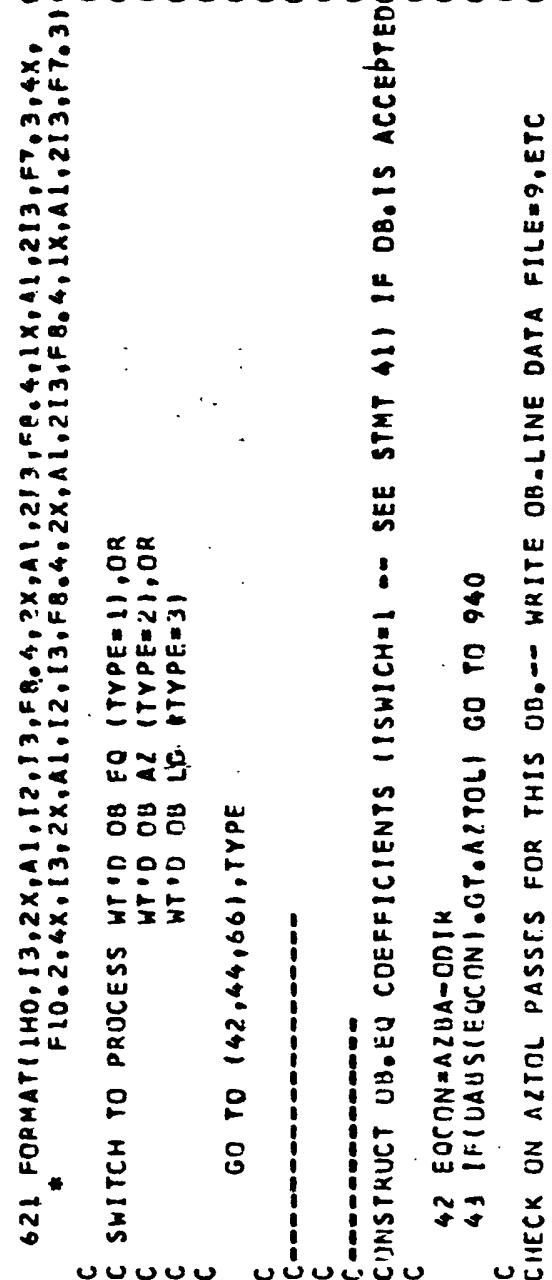

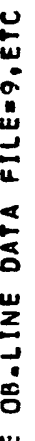

$\frac{m}{\alpha} \stackrel{\frac{\pi}{x}}{\frac{x}{x}}$

c

8 :

$n$
$\vdots$
0
$n$

כ高

on

$\overline{\frac{N}{\Sigma}} \overline{\frac{N}{2}}$

în

$\because$

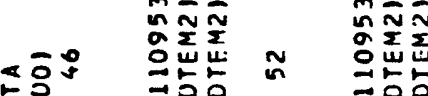

¿ c

象은

$\leq \frac{10}{2}$

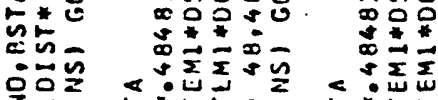

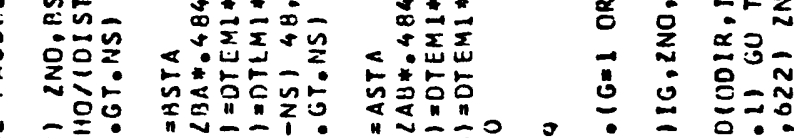

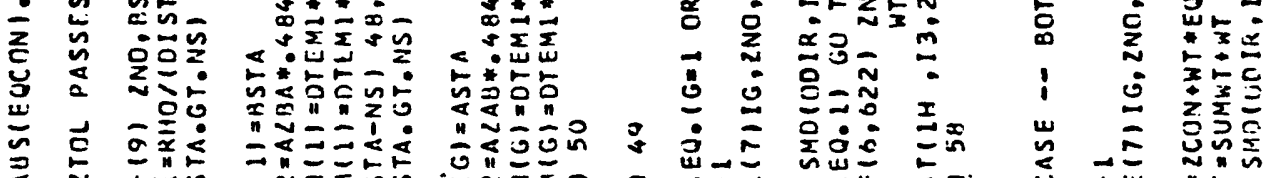

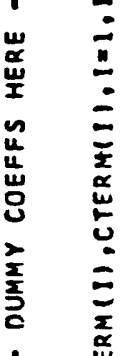

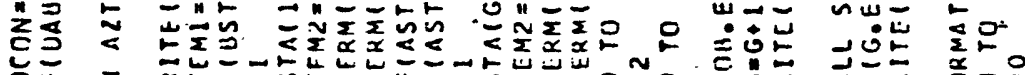

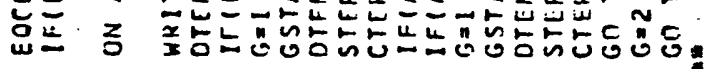

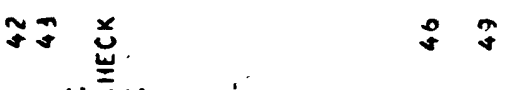

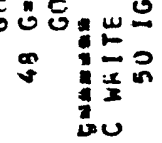

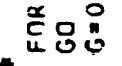

:

u

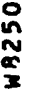




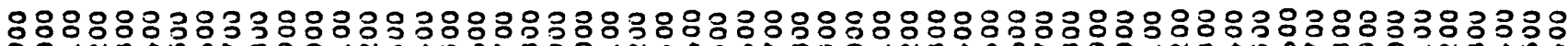

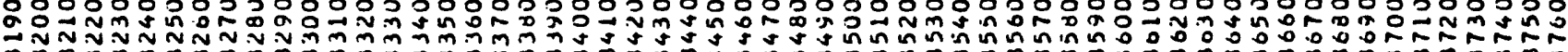

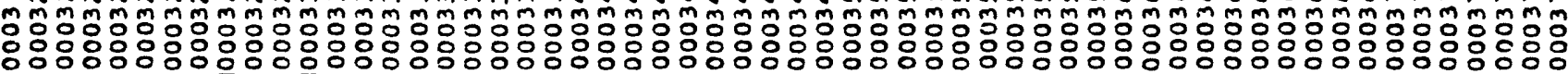

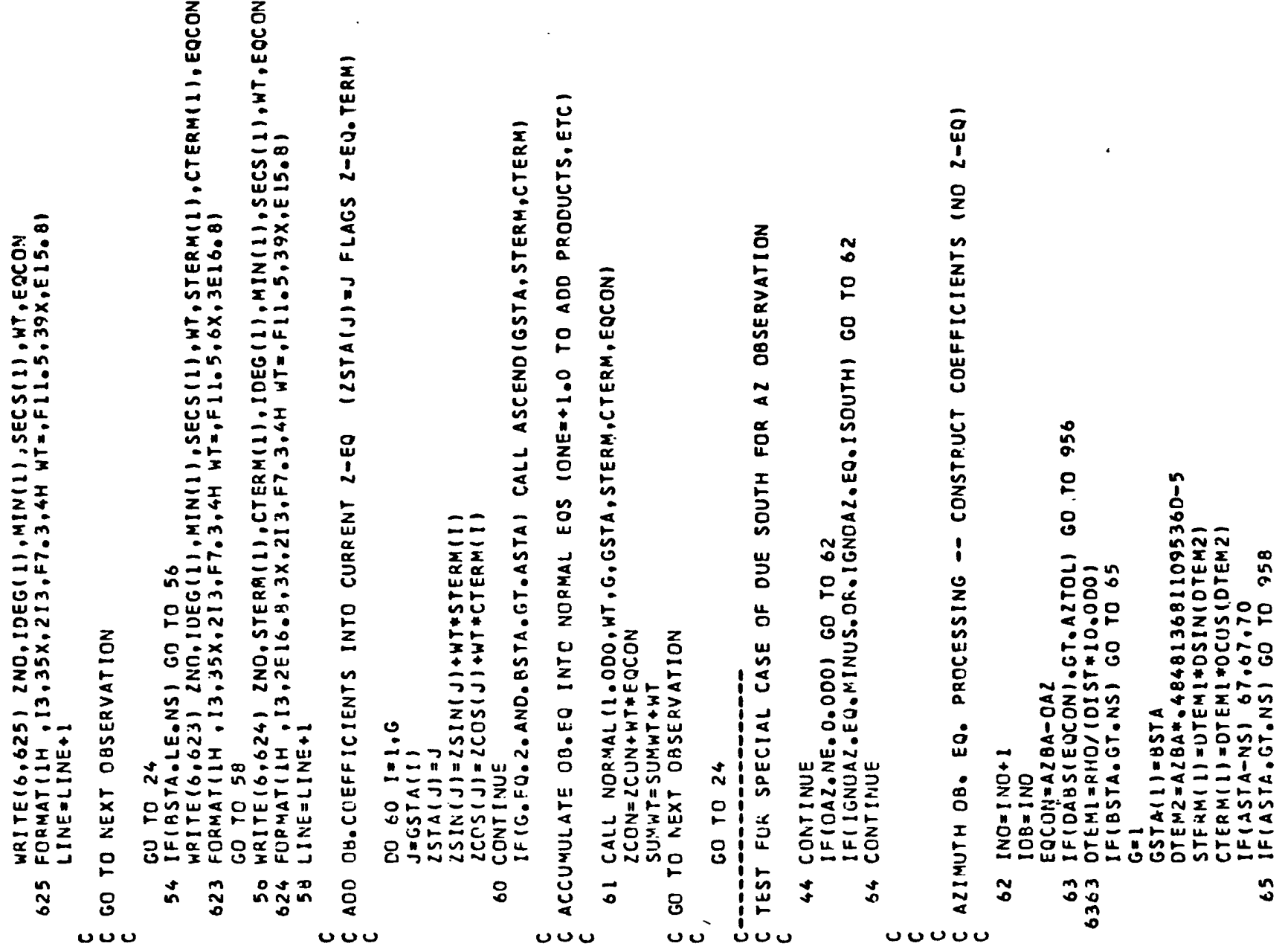

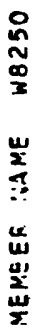




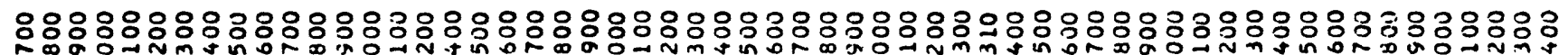

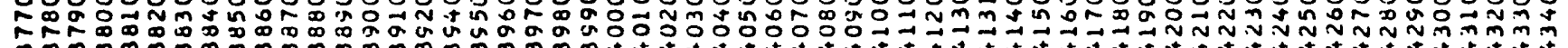

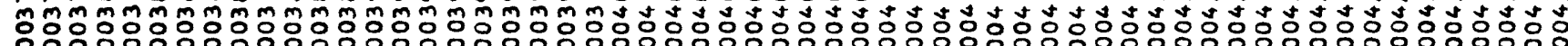
ஃั:

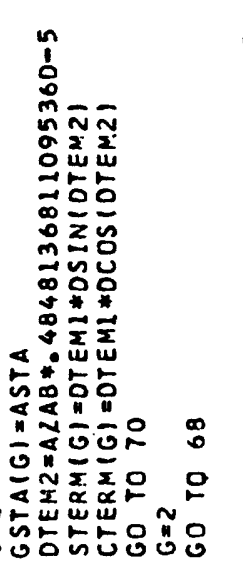

:

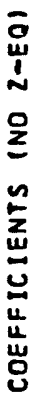

๖ 点

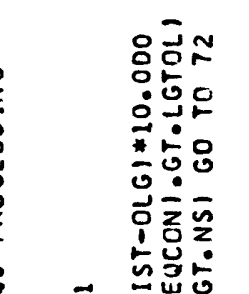

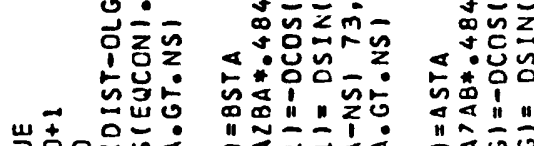

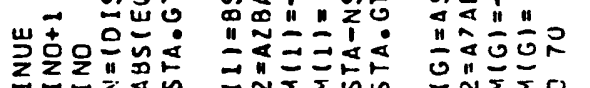

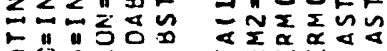

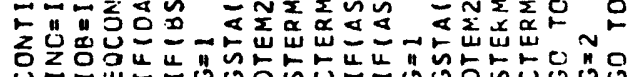

年

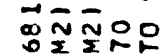

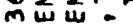
点点的范

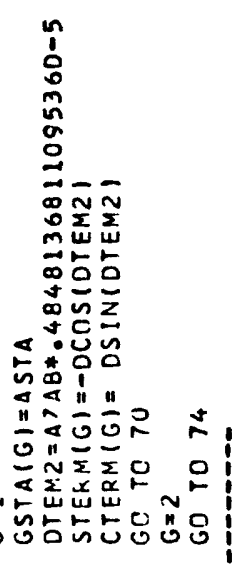

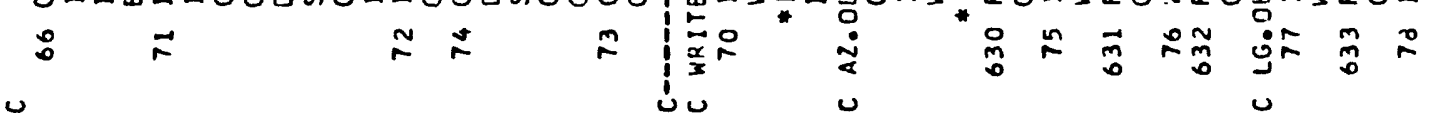

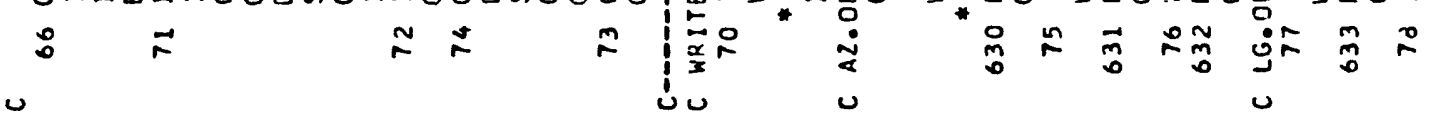

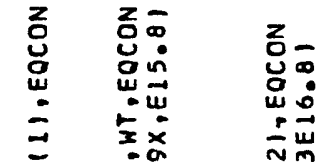

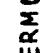

:ڤ

涔

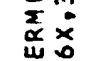

$5 \times$

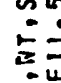

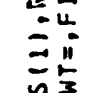

范

等

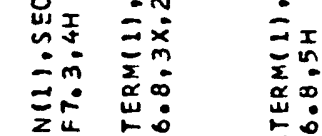

ํㅚㅇ 50

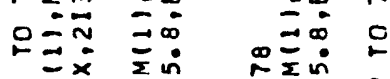

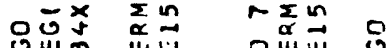

品骂 no mo

$\sum_{i=0}^{n}$

可

non

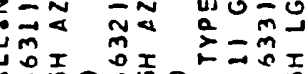

யँ

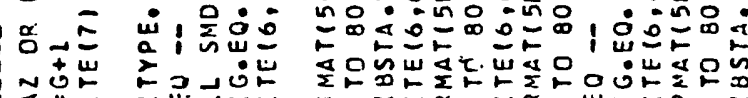

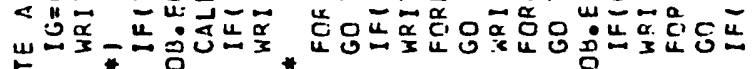




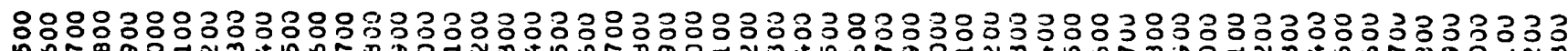

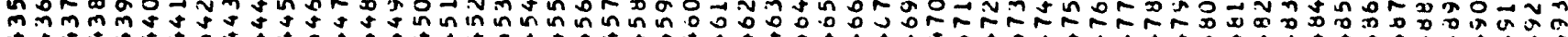

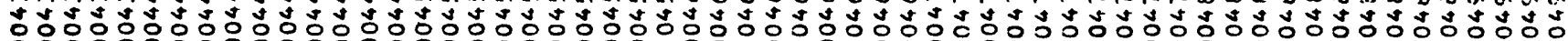

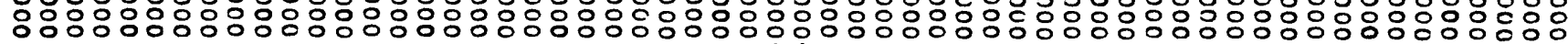

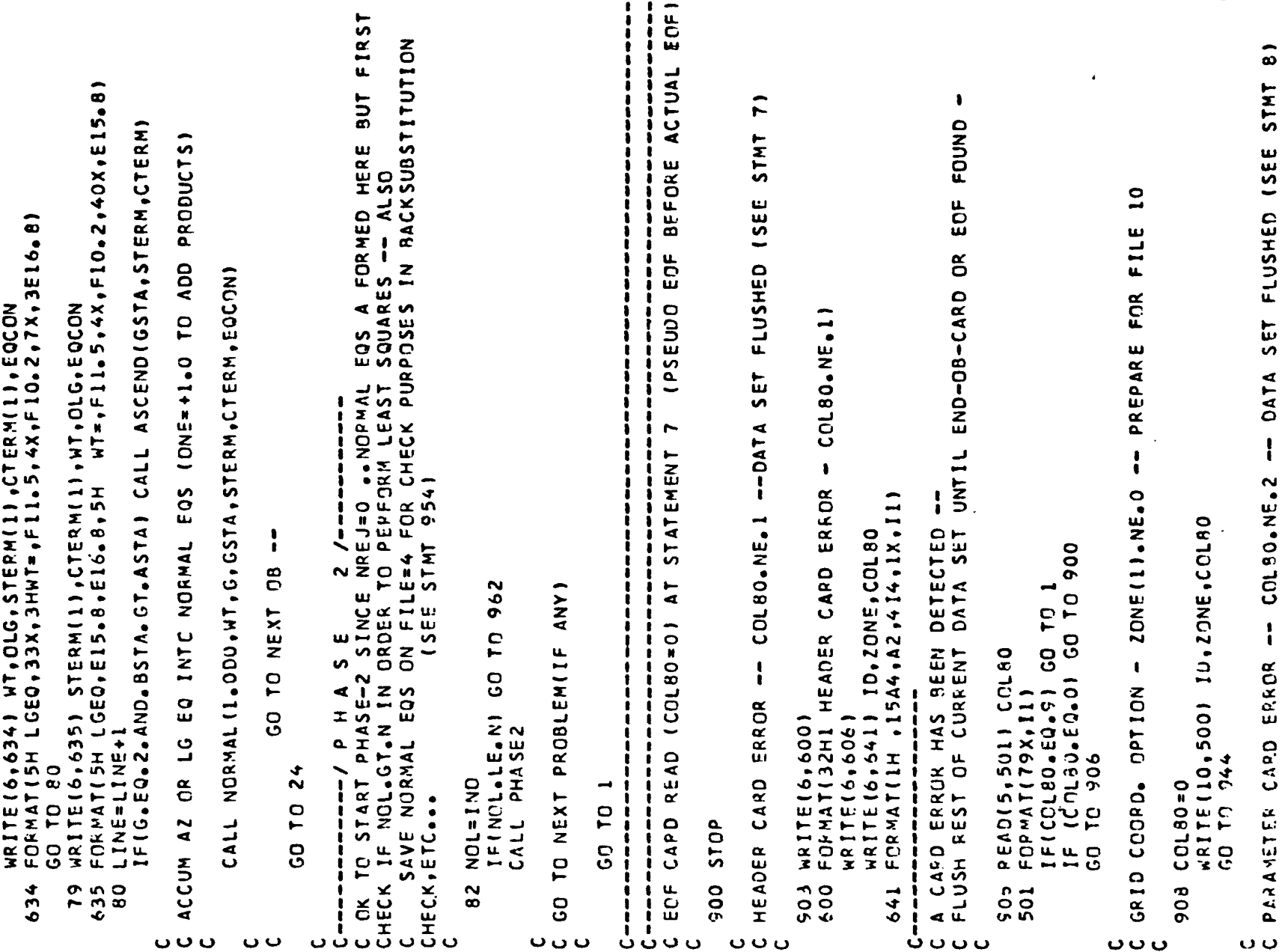

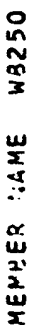




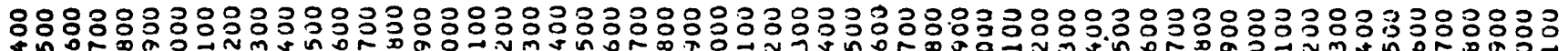

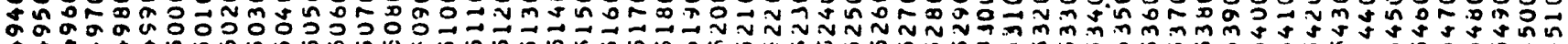

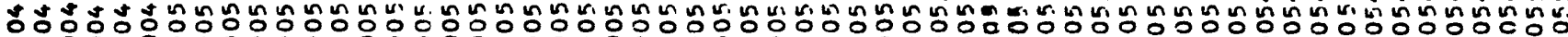

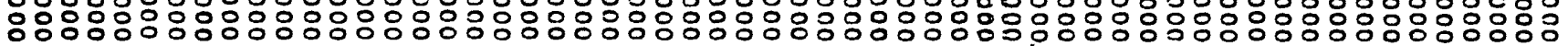

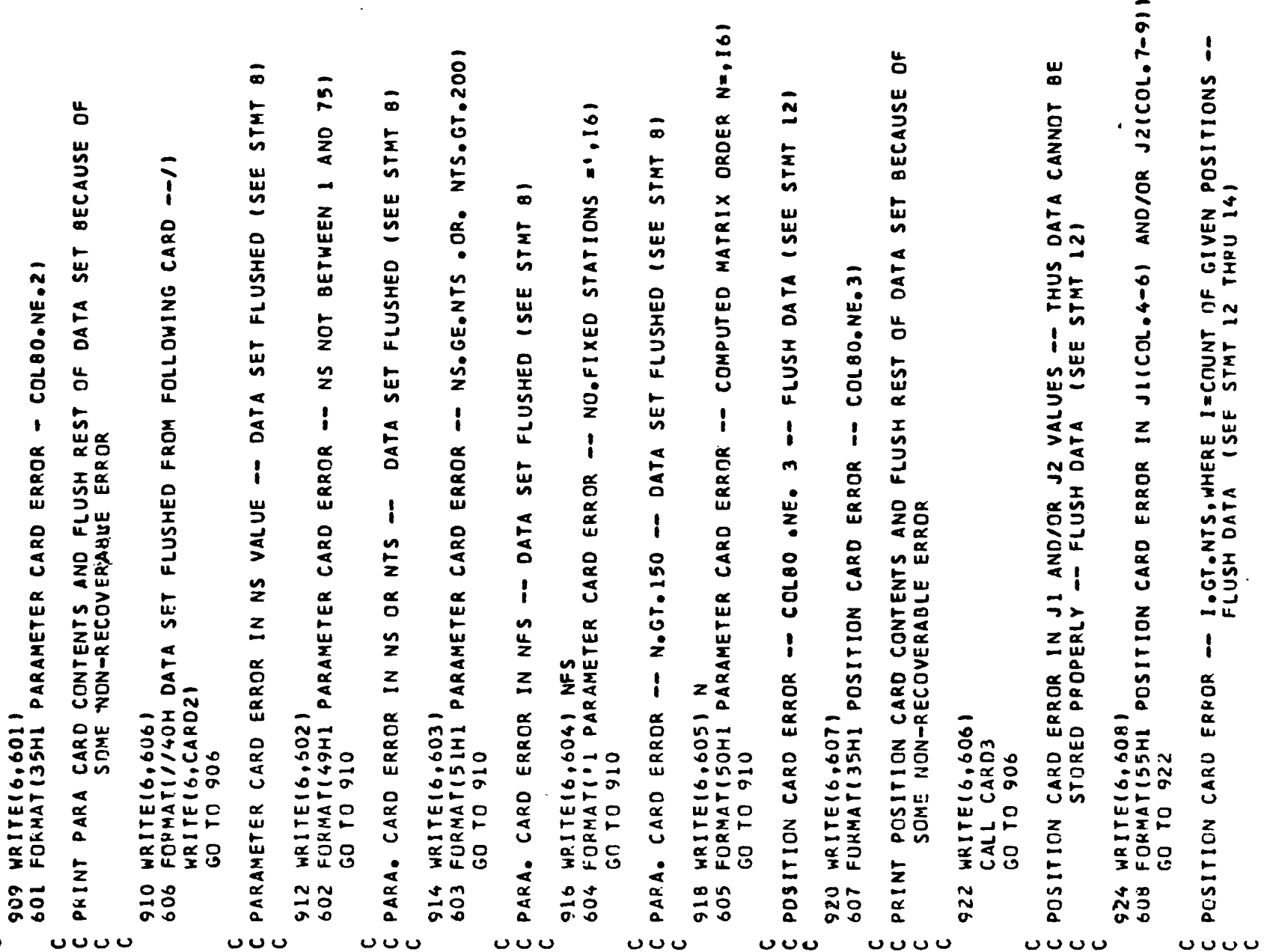




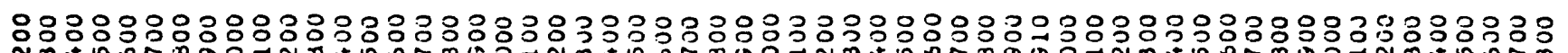
ñun

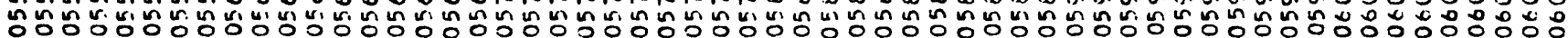
:

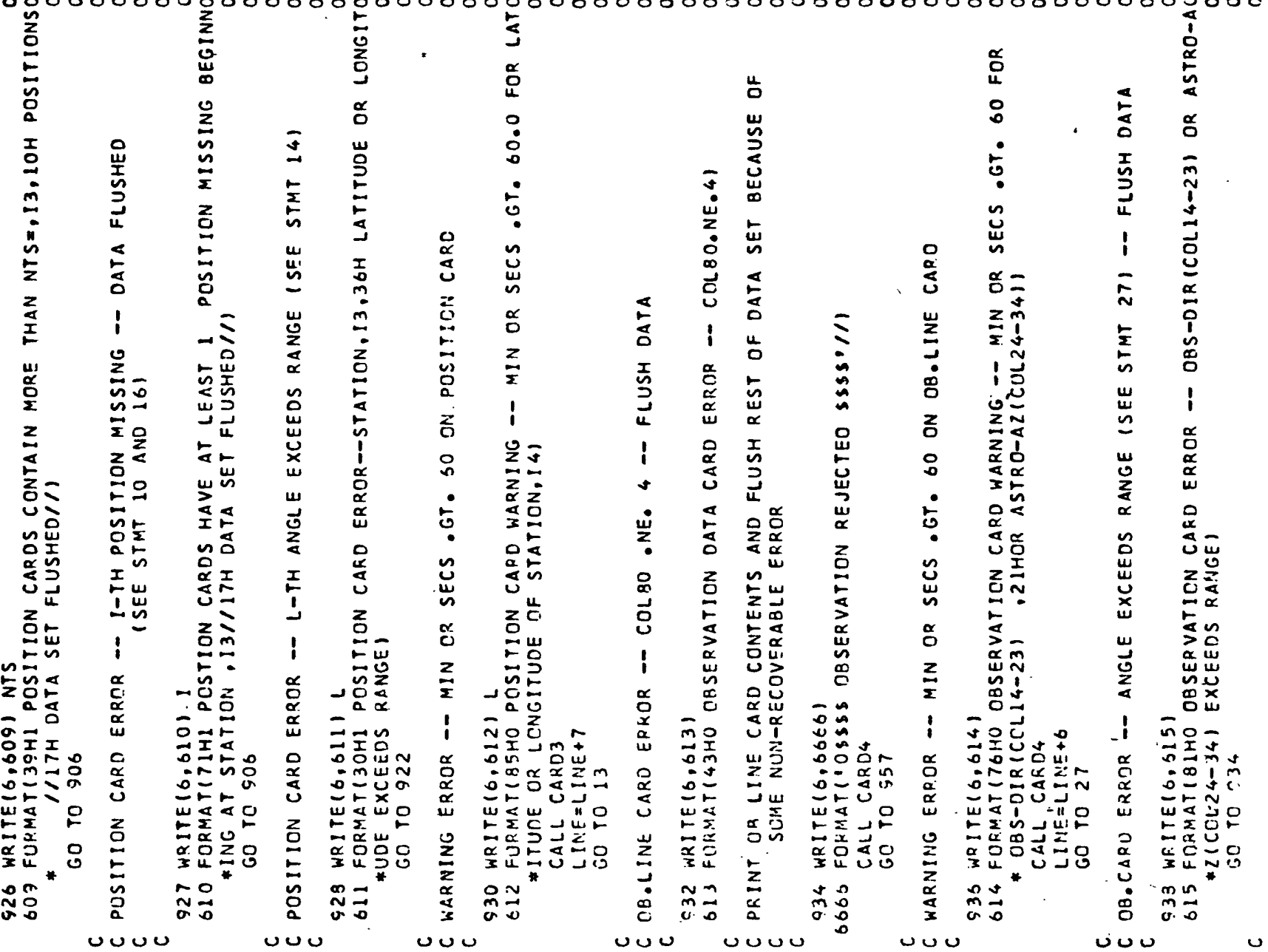

$\underset{\substack{n \\ \infty \\ \infty}}{x}$

$\stackrel{u}{\underline{\Sigma}}$

岂 


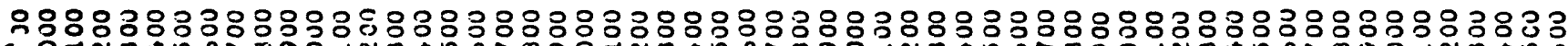

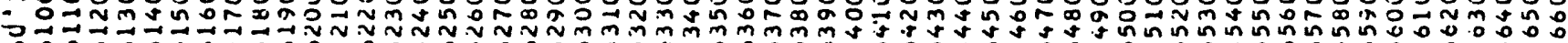

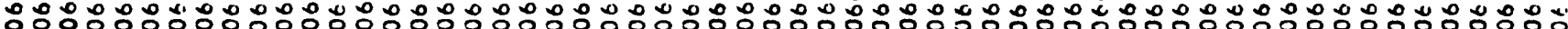

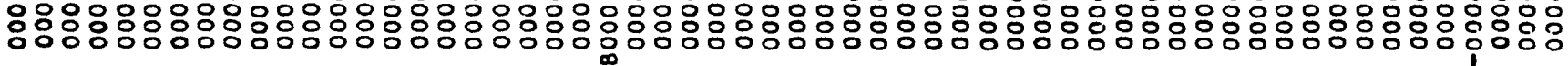

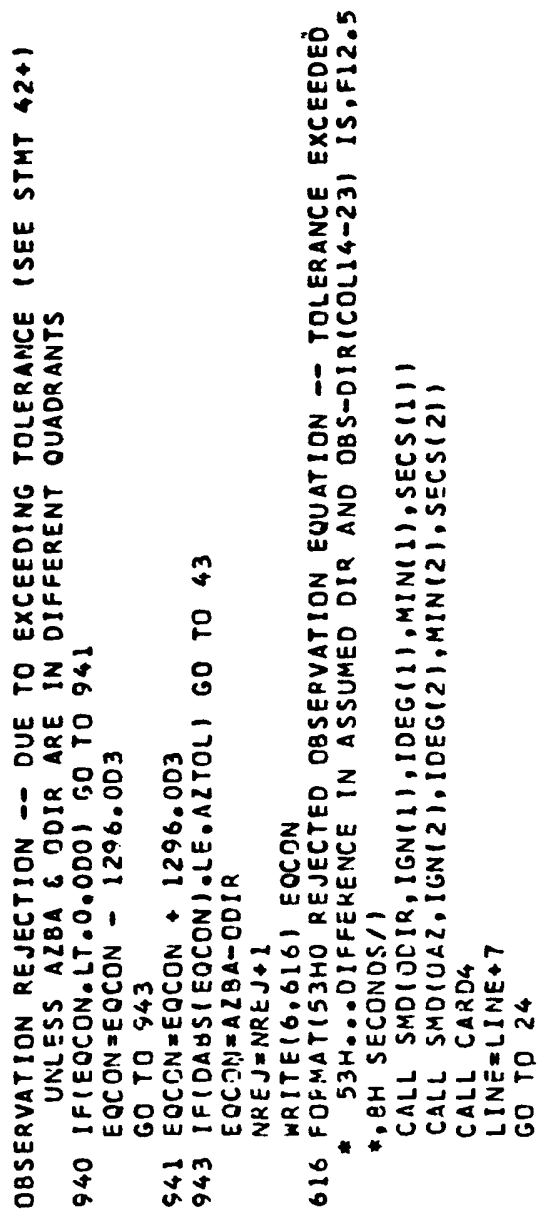

U

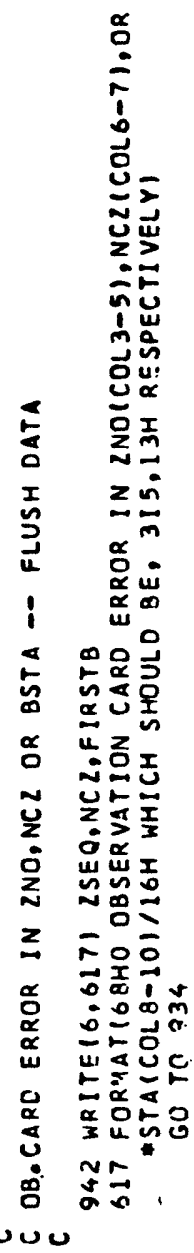

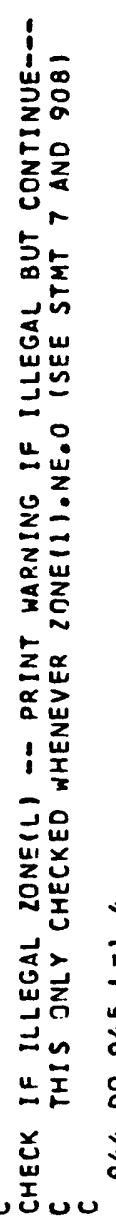

玄 1

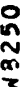
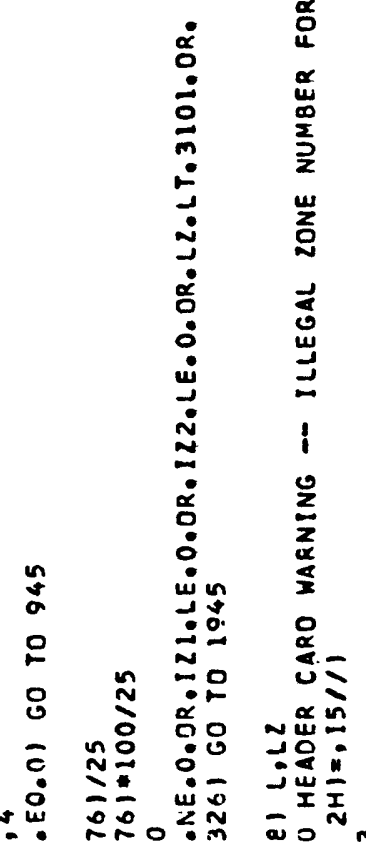

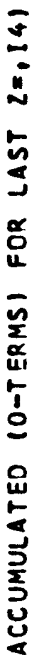

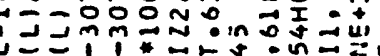

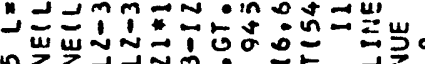

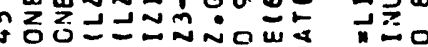
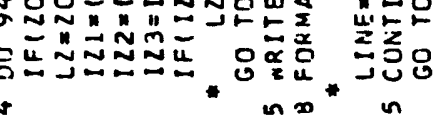

a

象
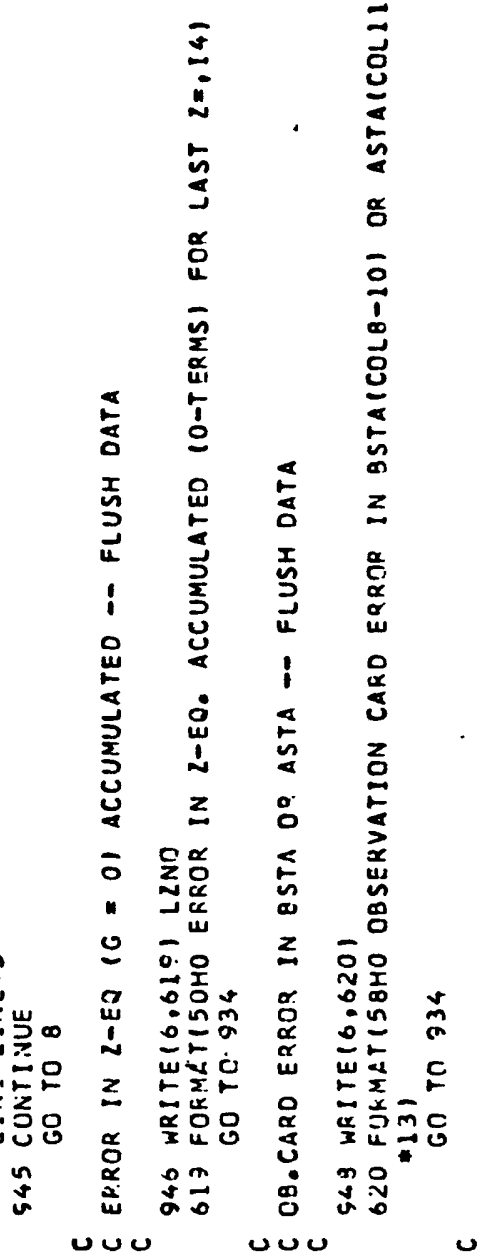


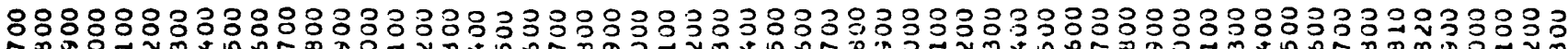

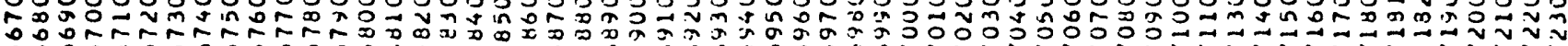

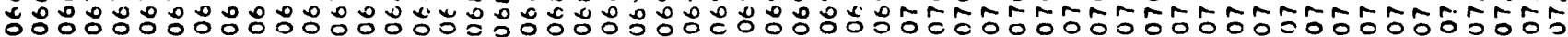
:

님

点

萡

$\underset{\stackrel{u}{i}}{\stackrel{a}{a}}$

(a)

$\dot{0}$

:

总

$\frac{1}{a}$

穿

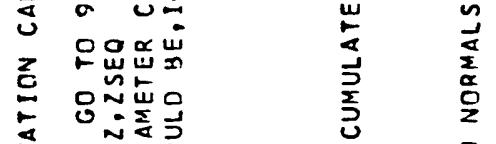

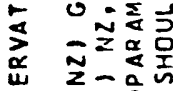

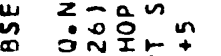

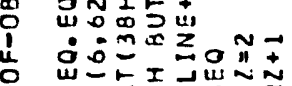

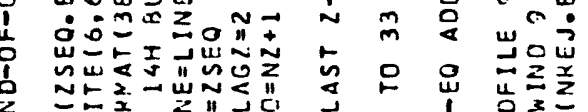

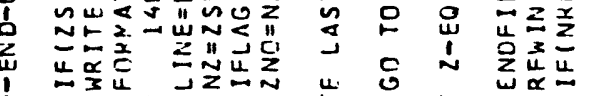

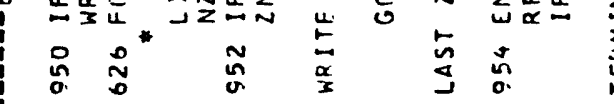

us

טu

৩ ৩ ৩

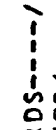

㟔高

这主

$\leqslant w \propto$

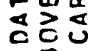

舟果

는

出岕崖

岁是鬿

I $2 \frac{a}{2}$

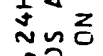

흥ㅁ

- $0 \frac{4}{4}$

幽岕

은

온돈

至吉这

究点学

品要

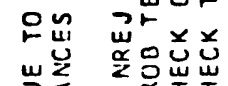

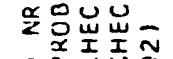

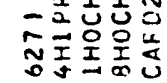

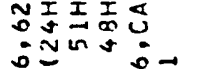

近皆

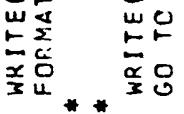

a

ก

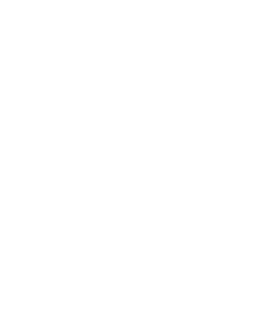

$n$
$z$
$o$
0

늘

梁这

岂出

마념

는

员品告.

전맘

웜영

wם -:

궁

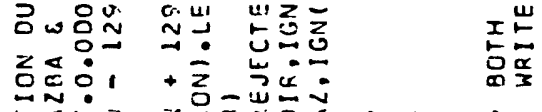

음

岁

品こシう

1 出出

के

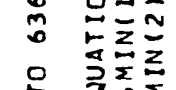

인

- $5 \frac{5}{5}$

뭉

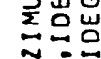

$\stackrel{4}{4} \div$

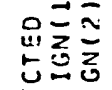

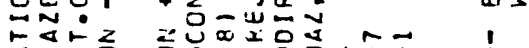

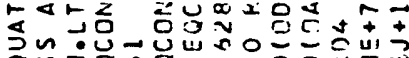

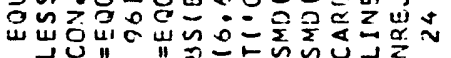

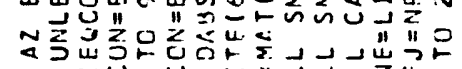

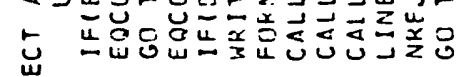

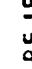

iñ $\stackrel{\infty}{\sim}$

৩ ৩

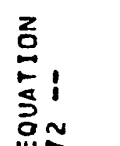

品

拄

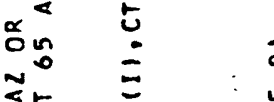

造占

u出

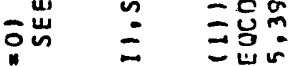

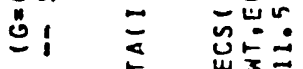

w

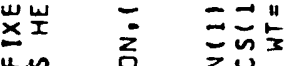

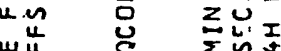

ख嵌 ㄴ.

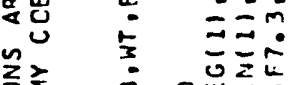

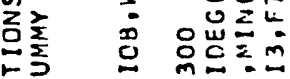

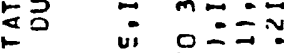

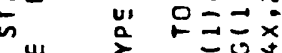

I皆 え

w $=$ u

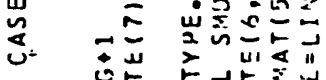

a

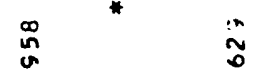

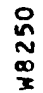

$\frac{14}{2}$

$x$ 


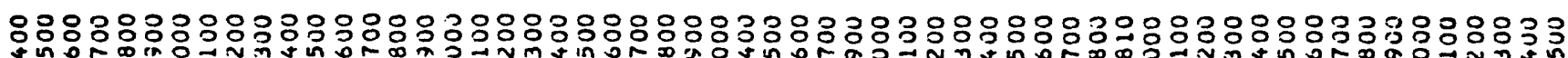

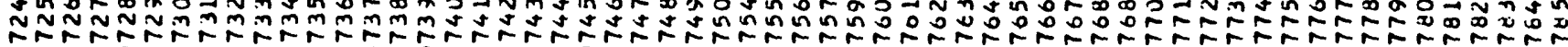

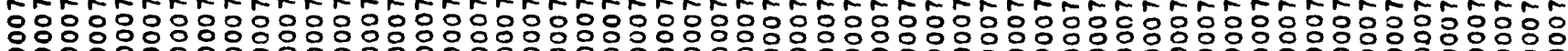

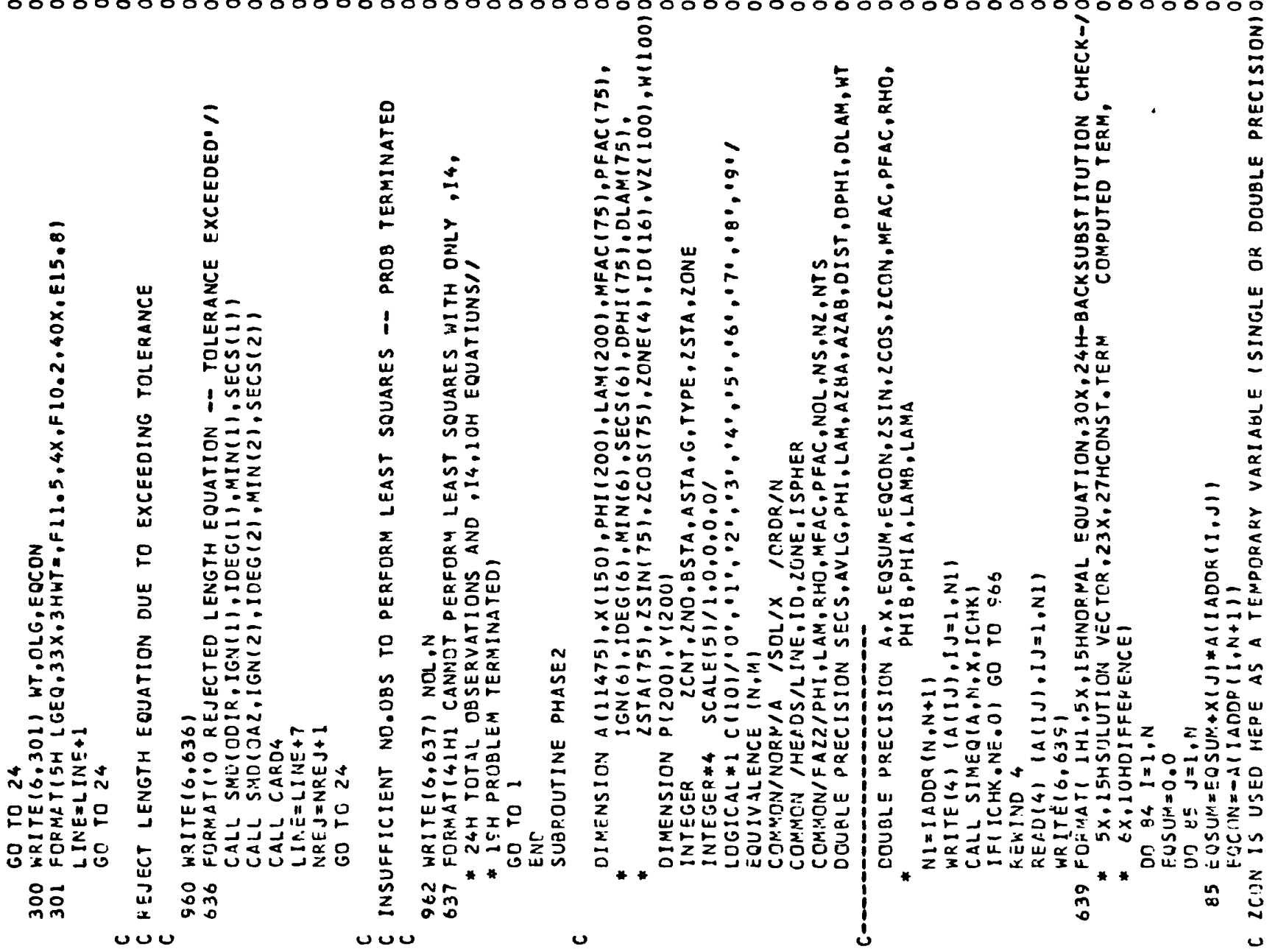

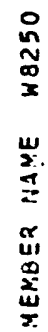




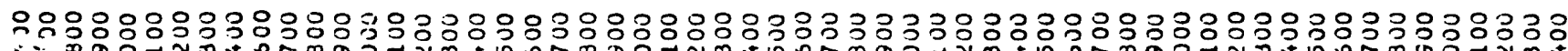

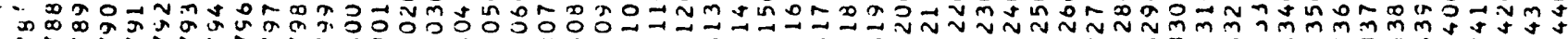

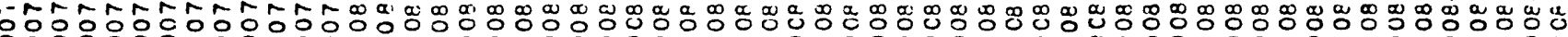
০০ঃ:

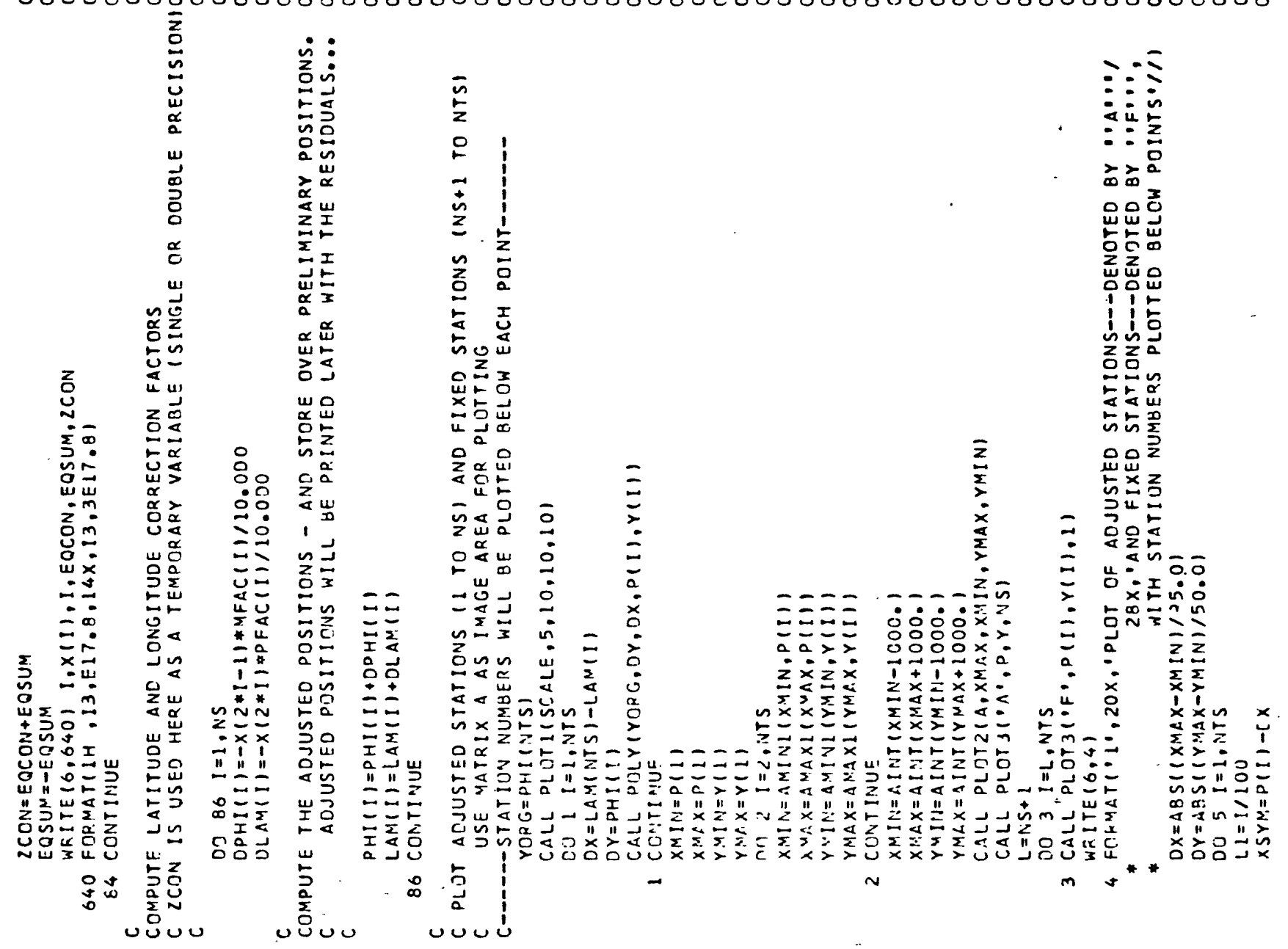

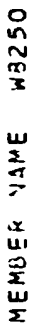




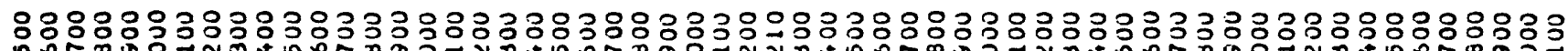

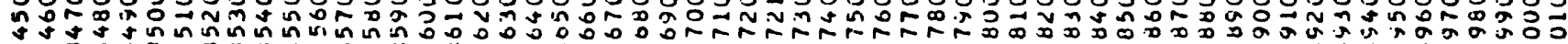

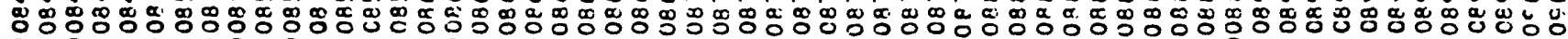

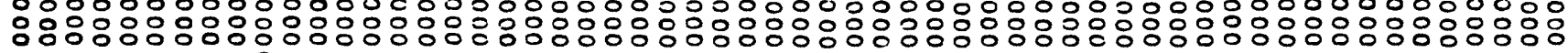

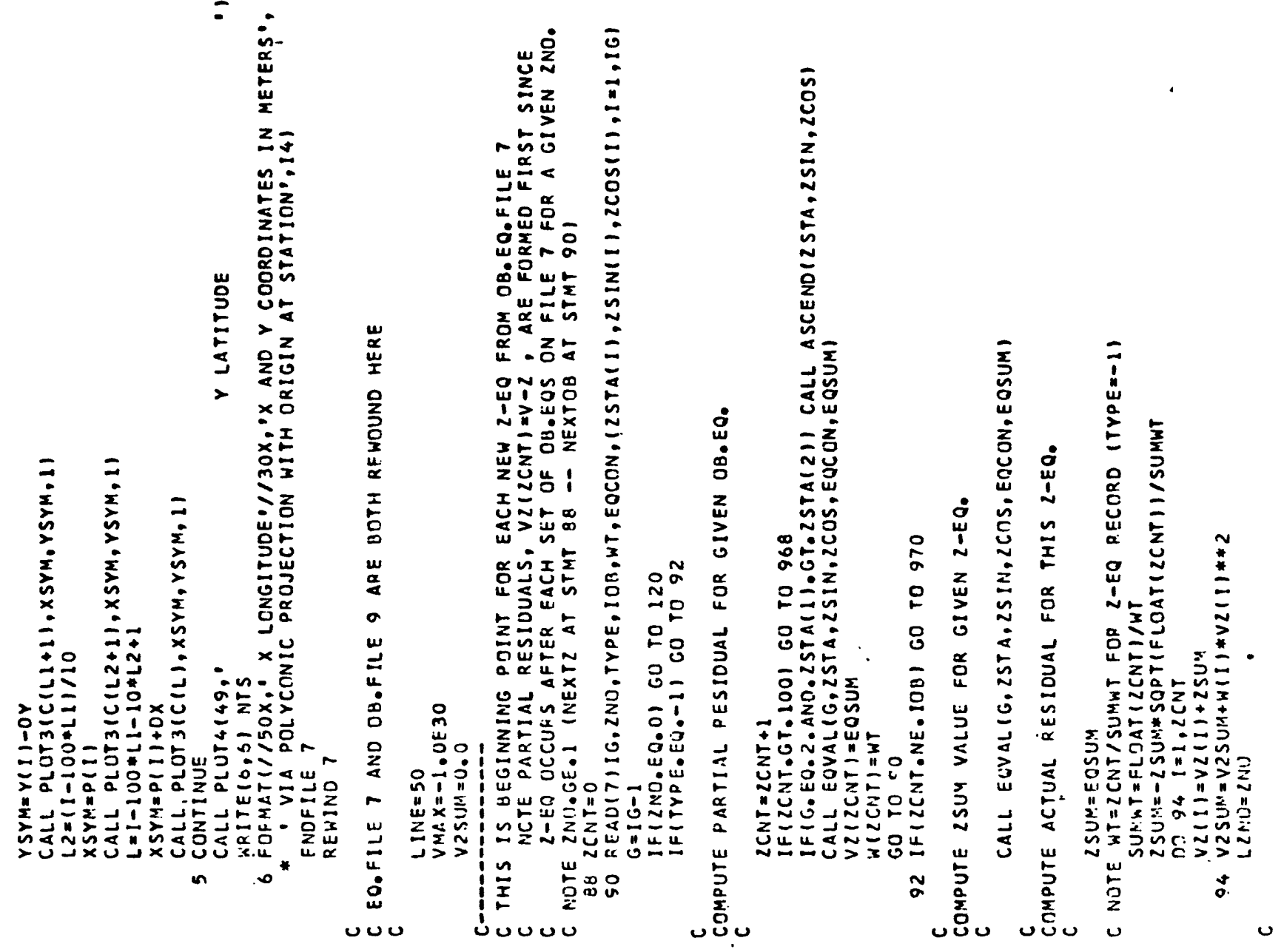

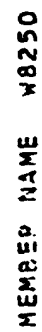




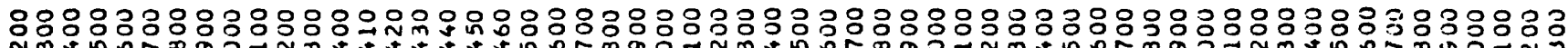

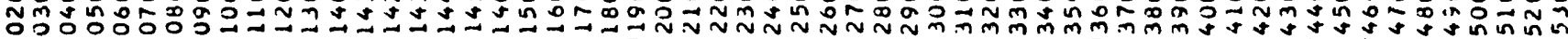

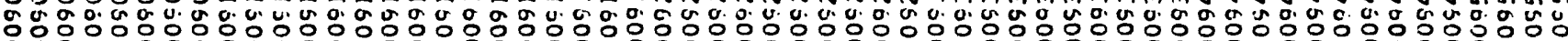
:

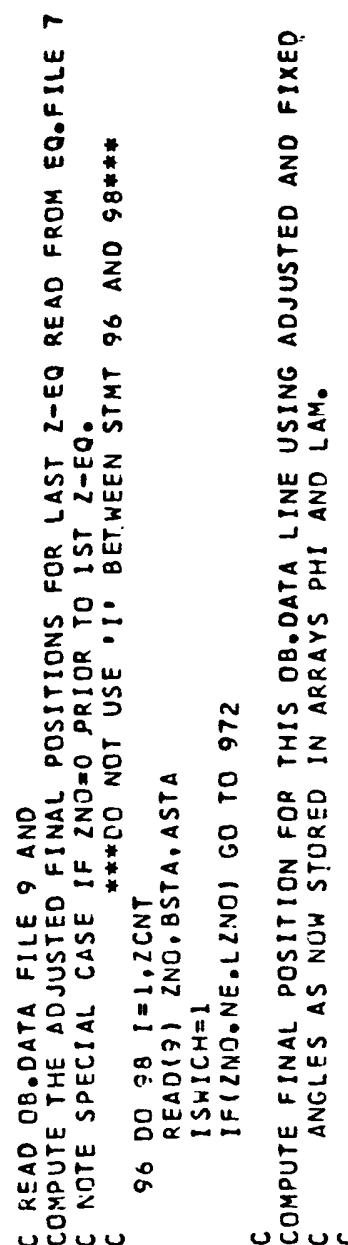

ưu

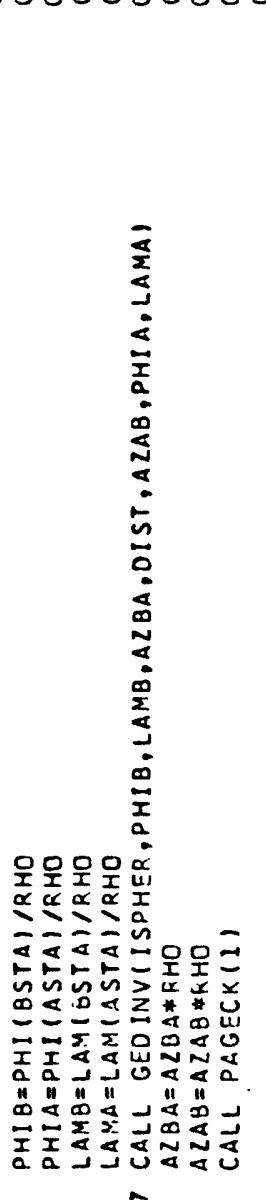

岁

৩u

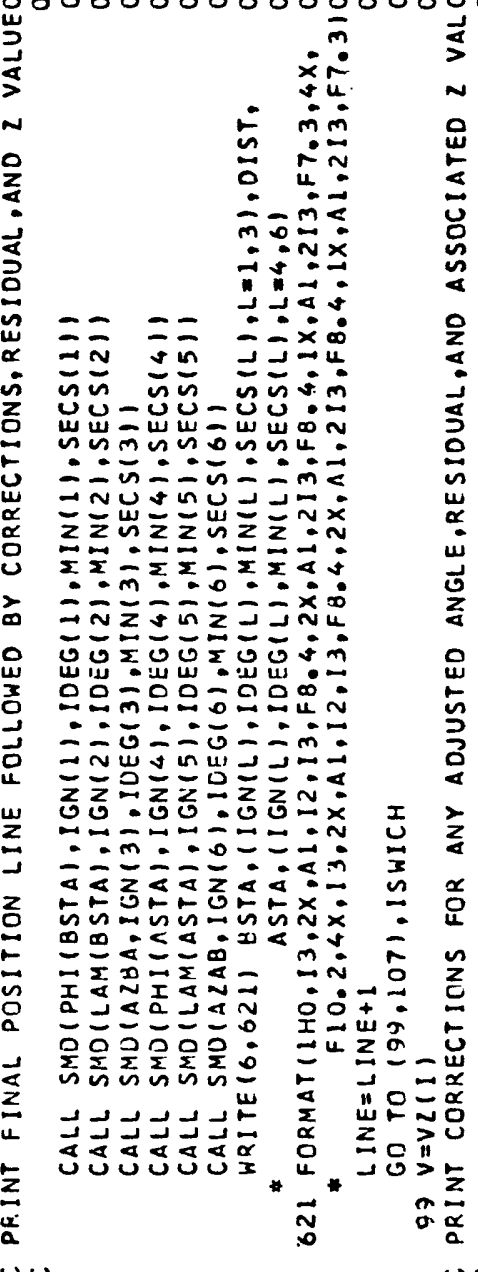

u

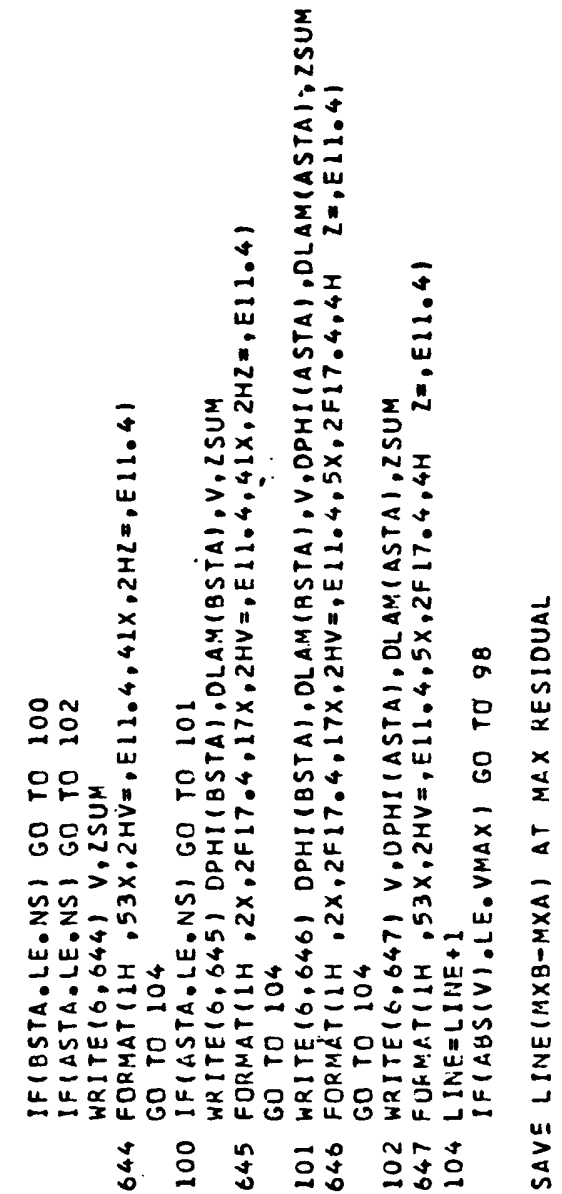




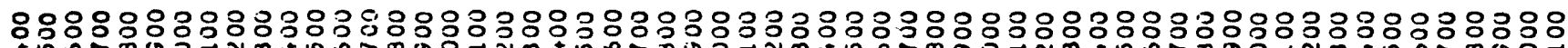

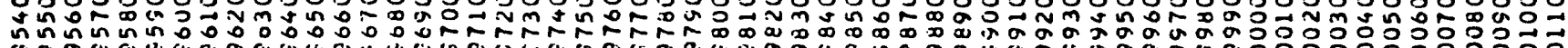

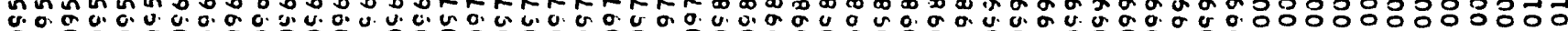

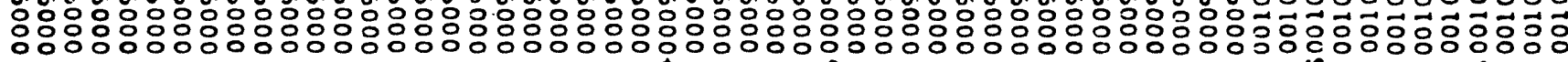

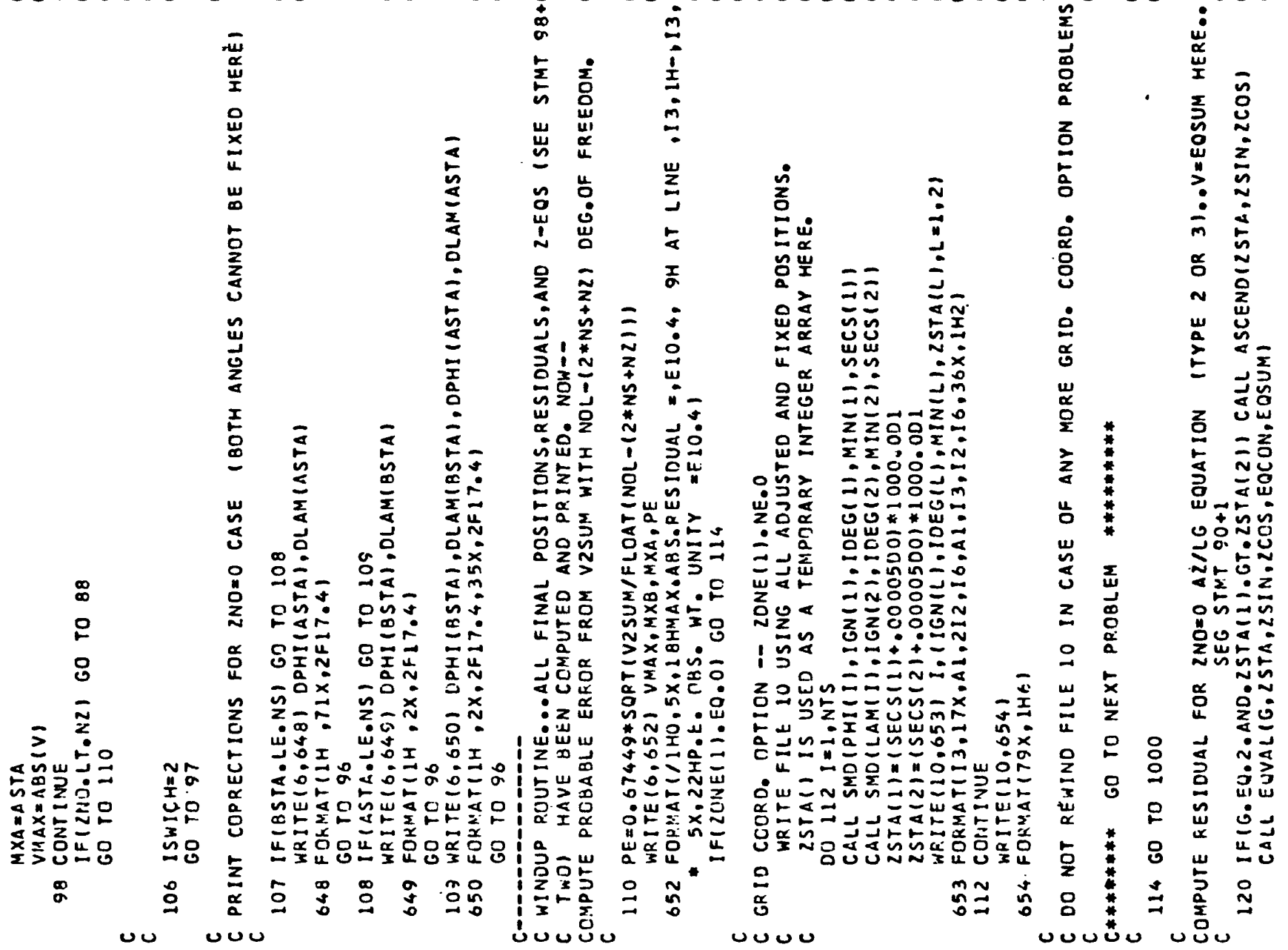

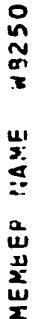




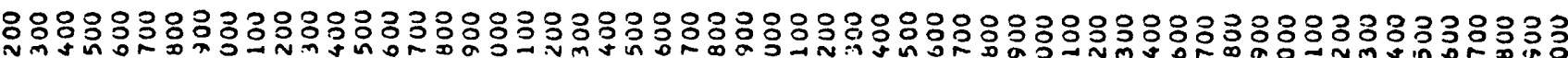

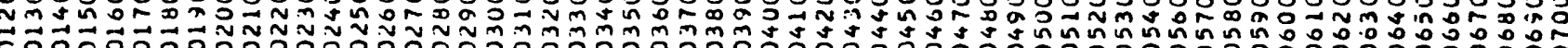

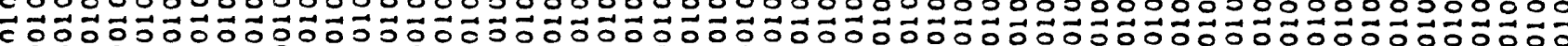

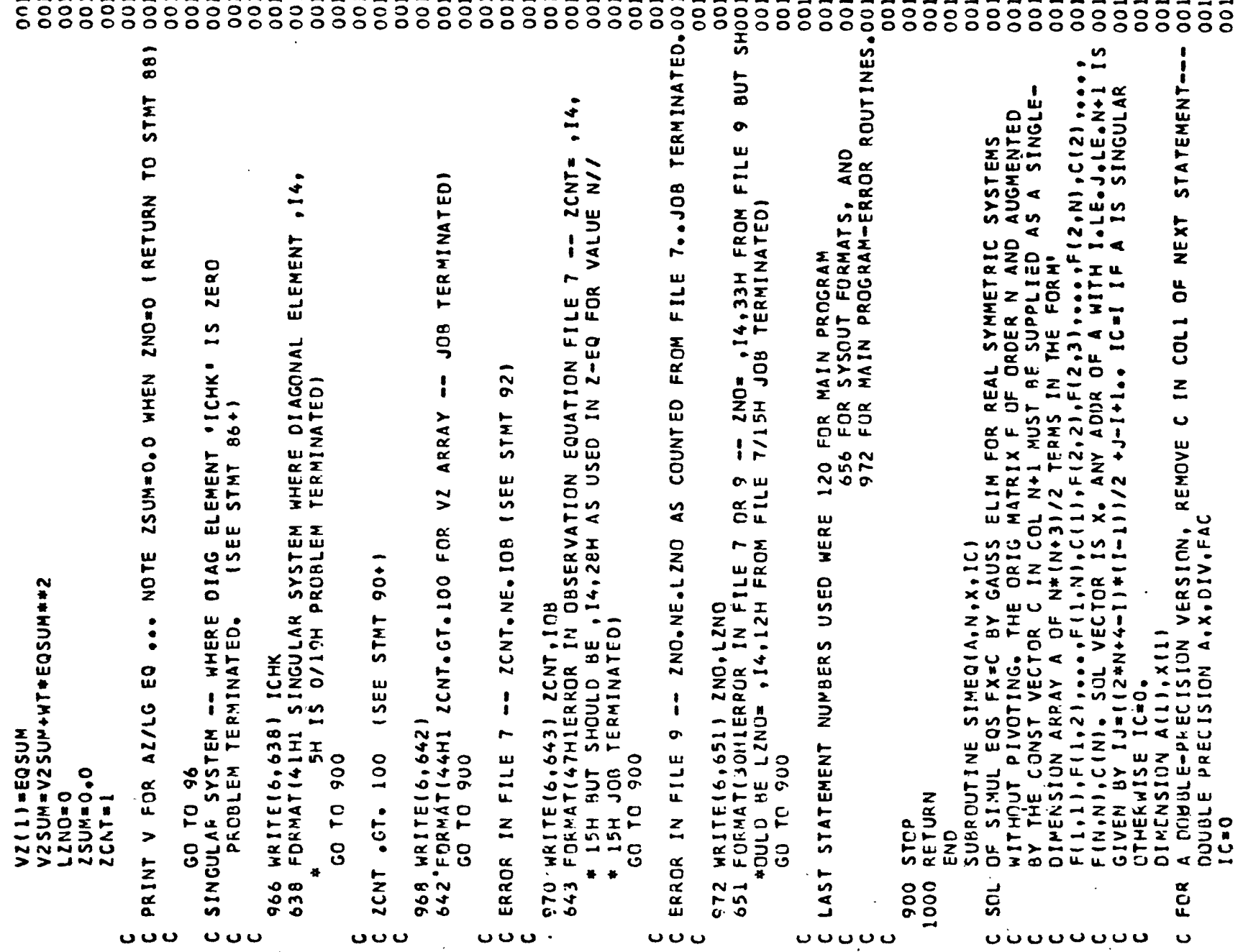

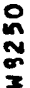

$\underset{\Sigma}{\mathbf{I}}$

占 


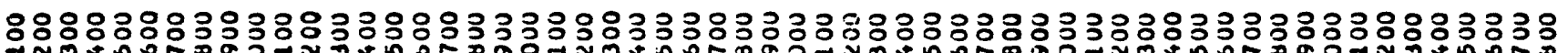

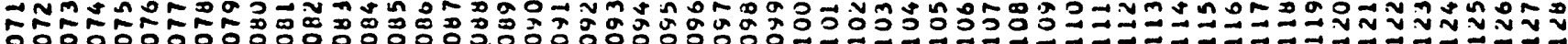

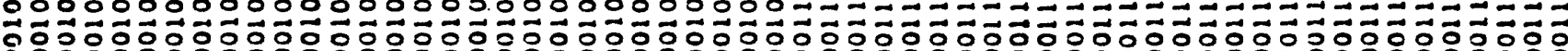

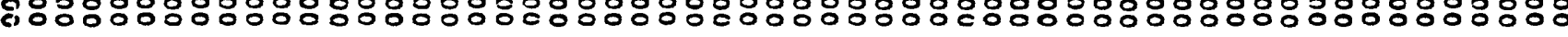

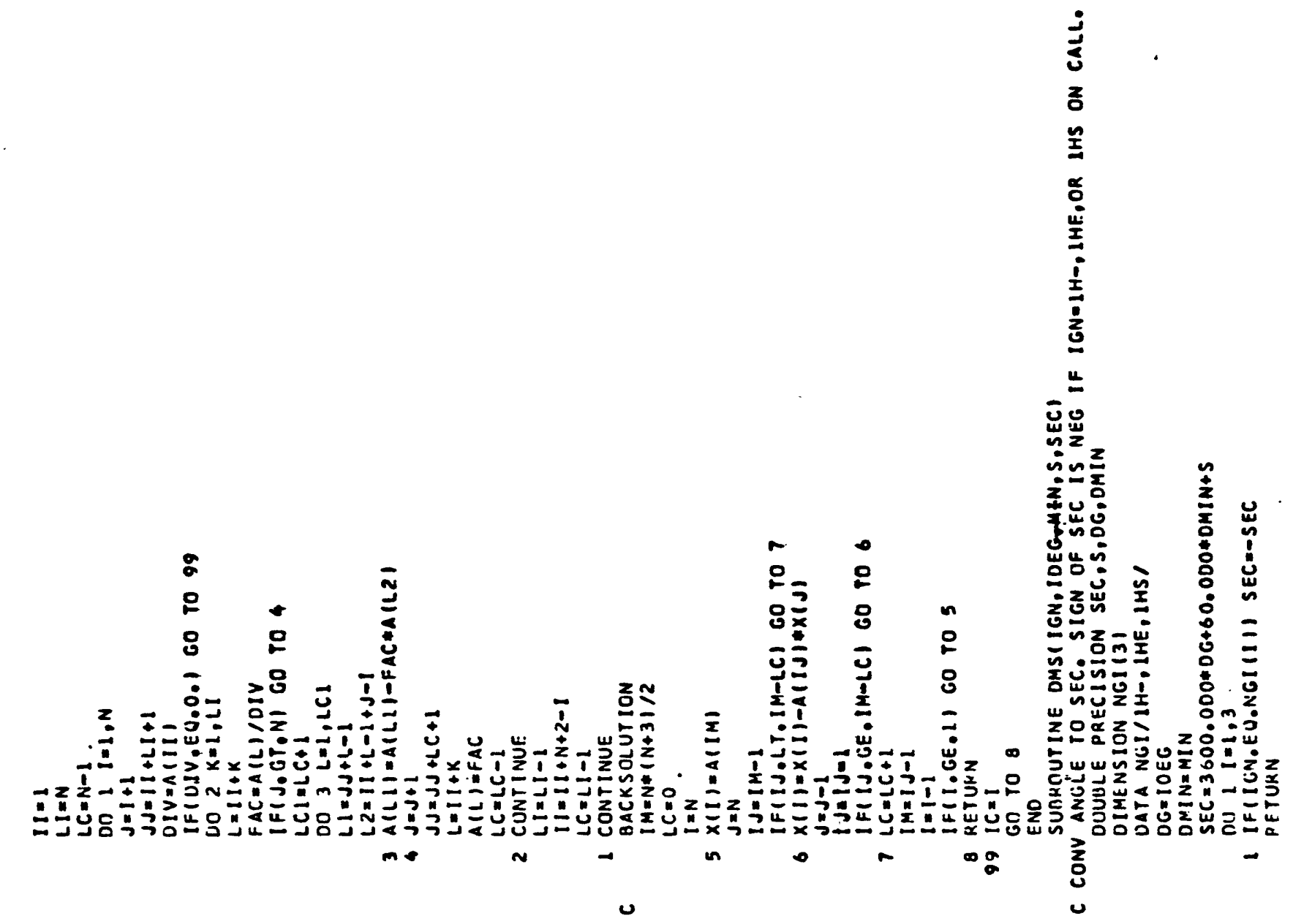




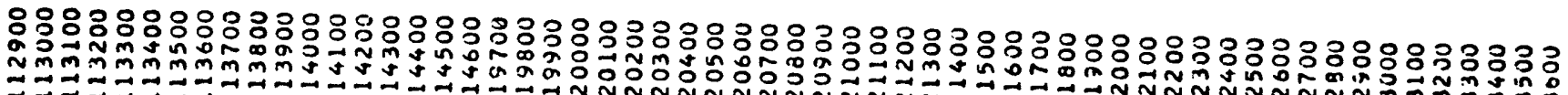

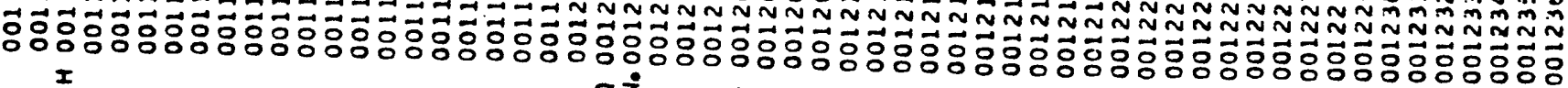

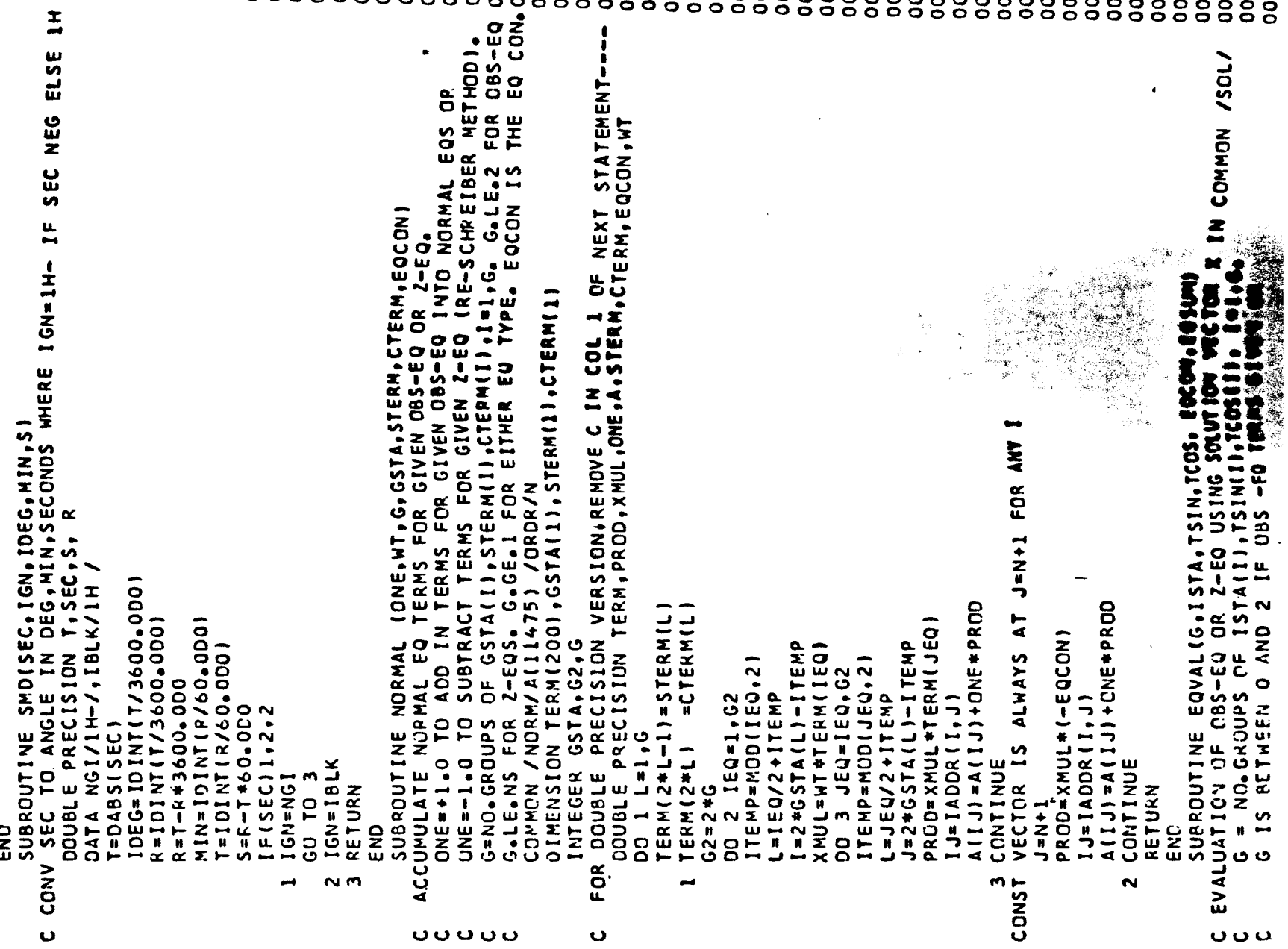




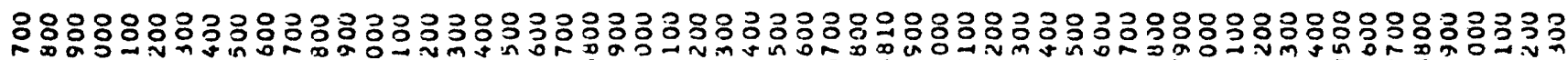

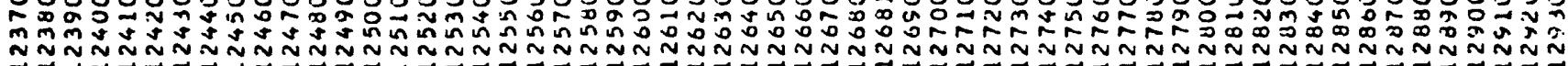

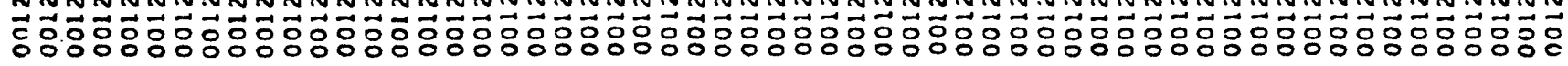
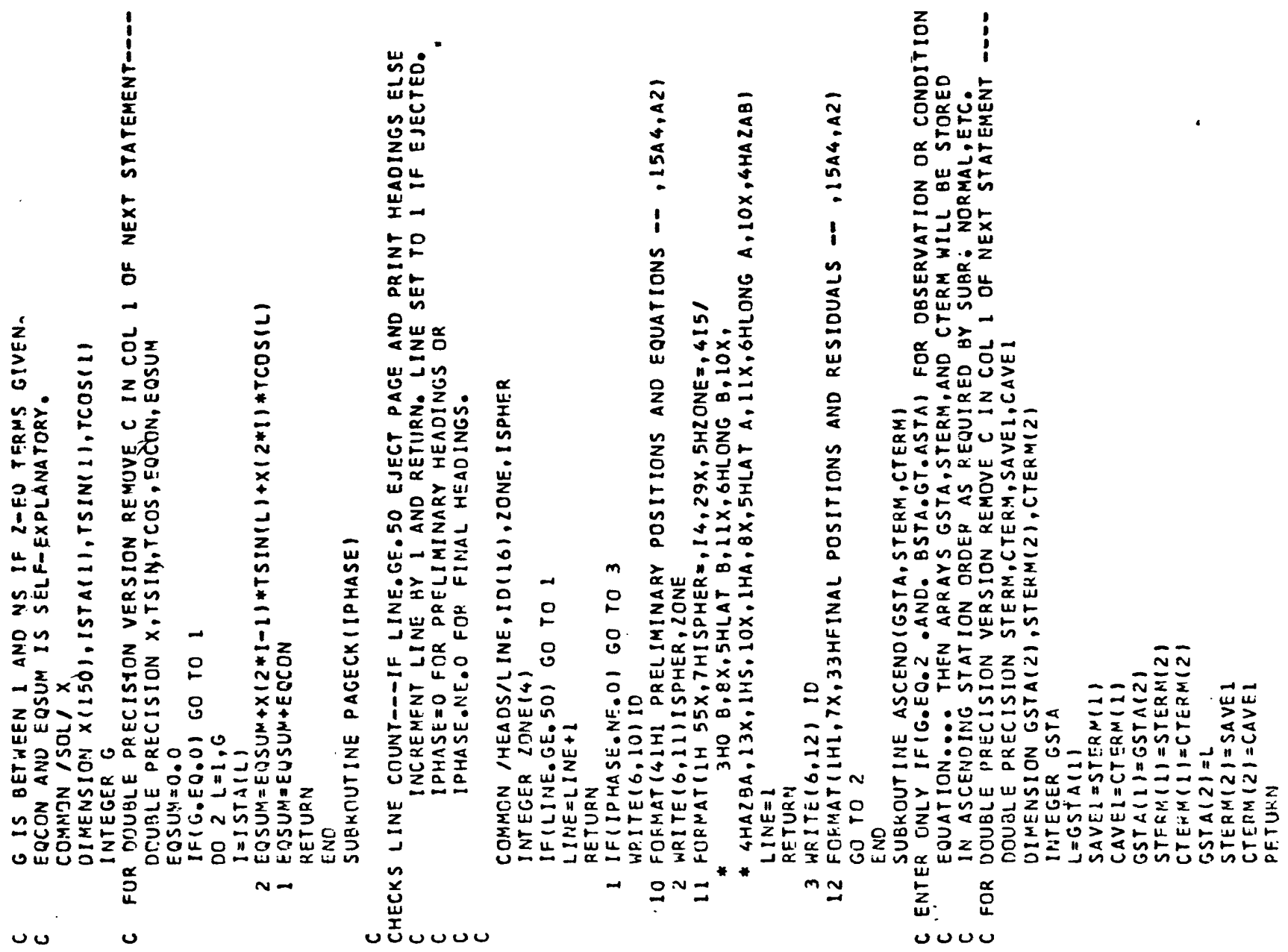

足 


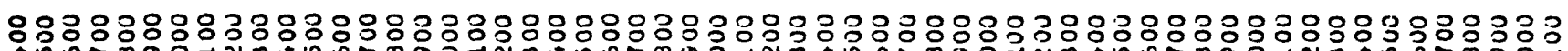

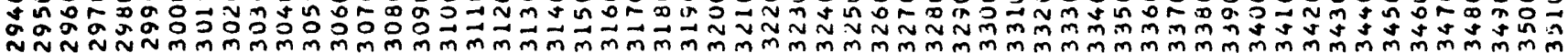

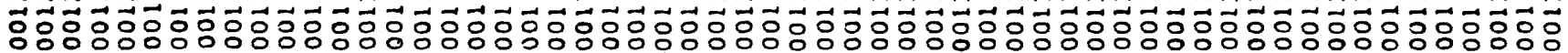

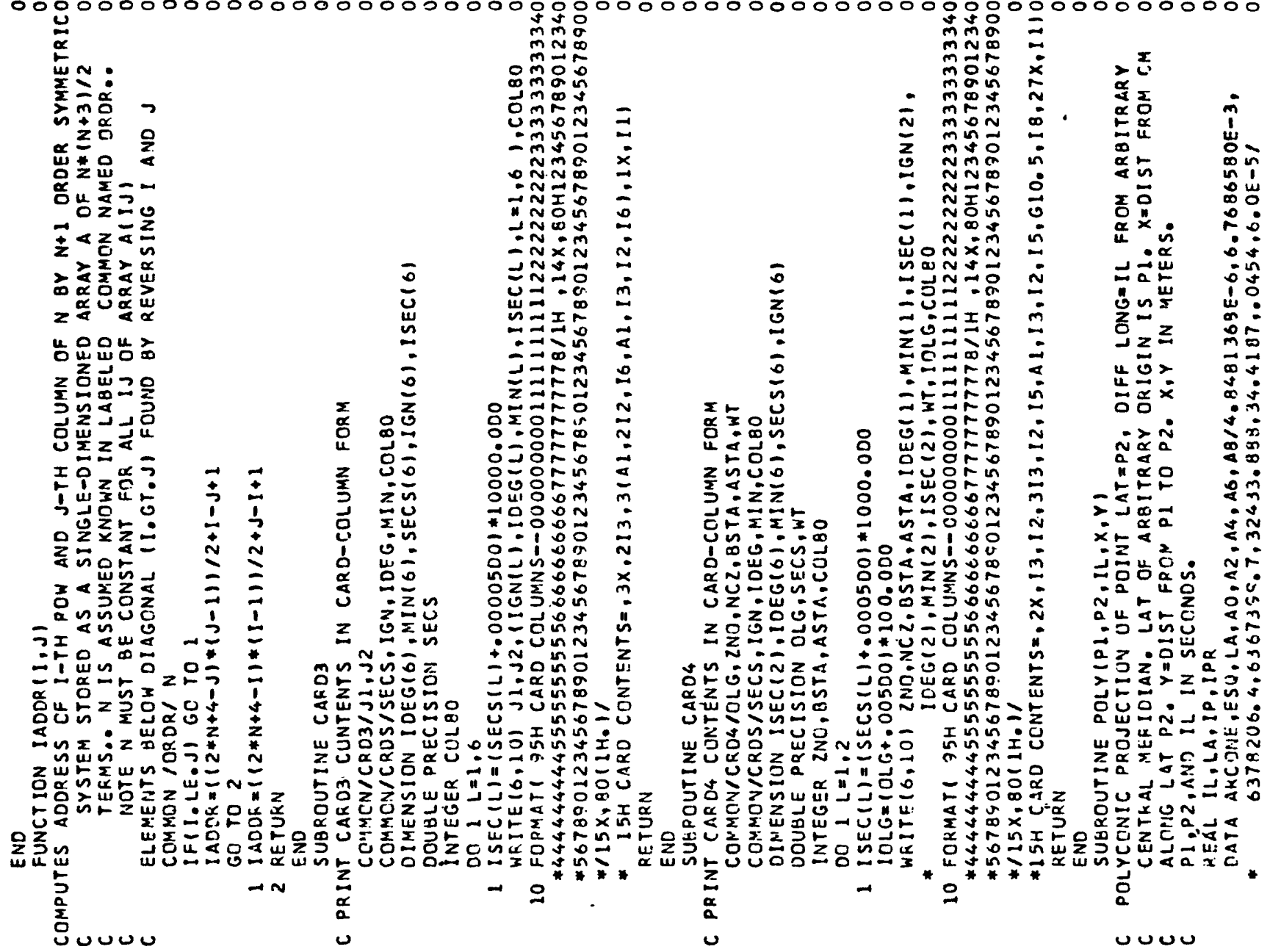

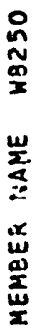




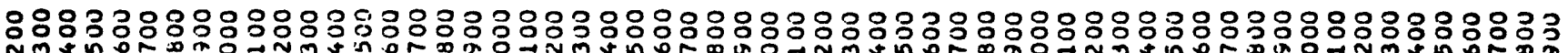
Niminn

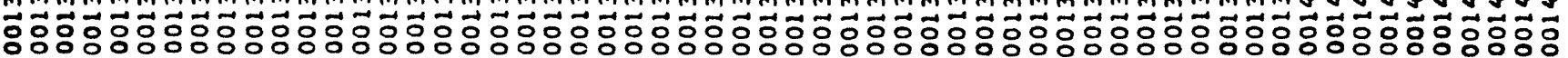

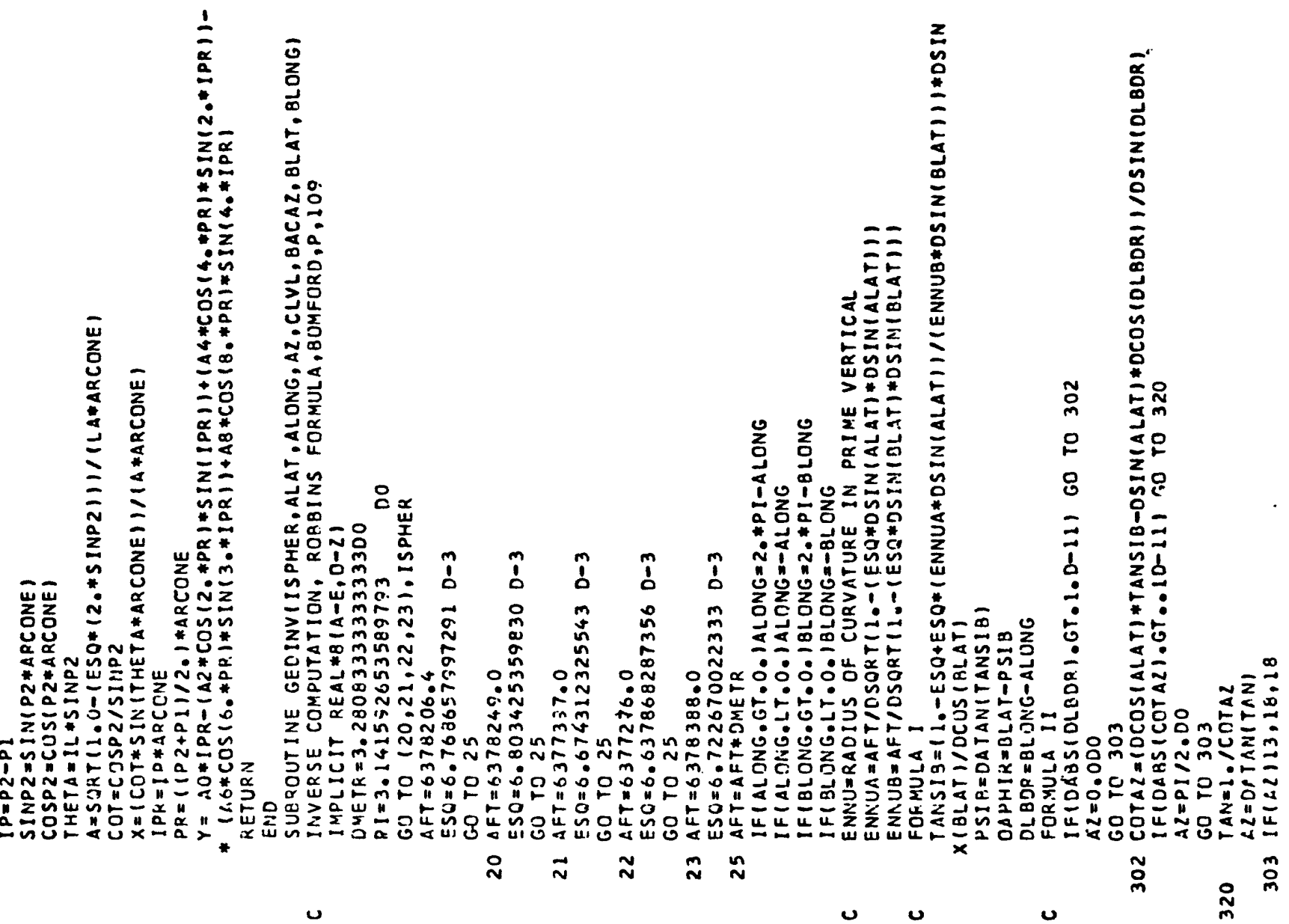

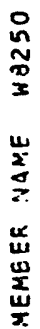




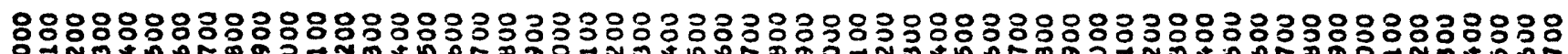

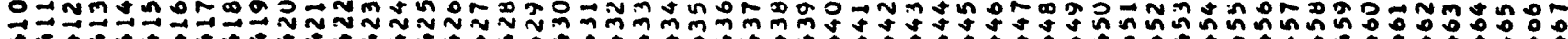

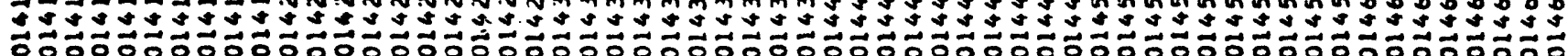

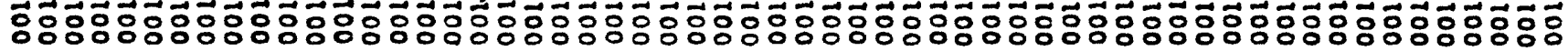

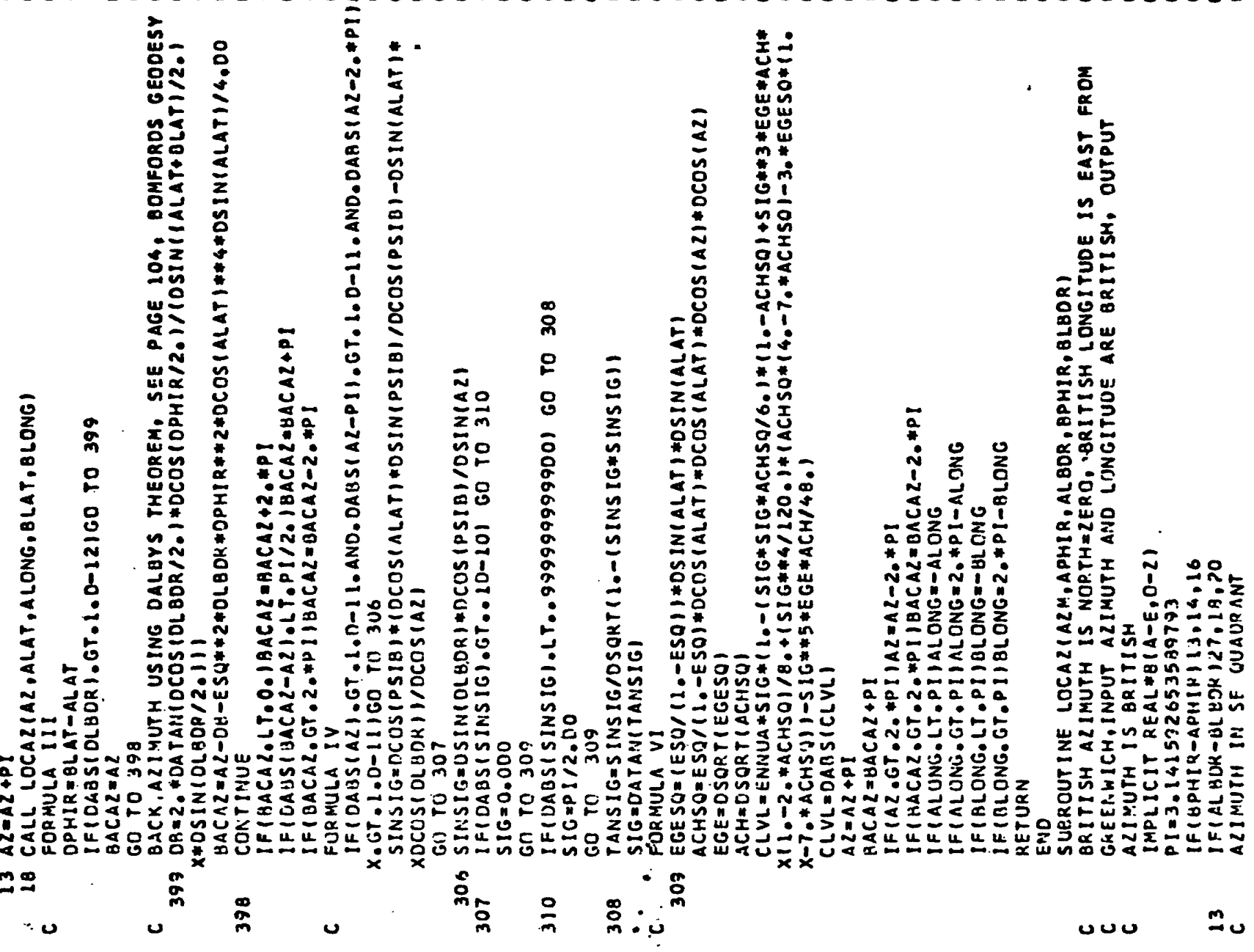

悥

필

㟧 


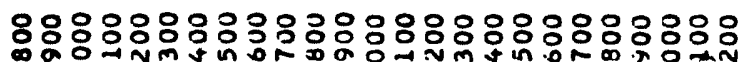

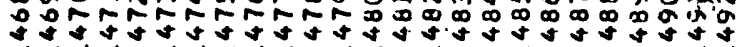

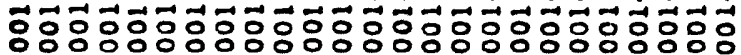

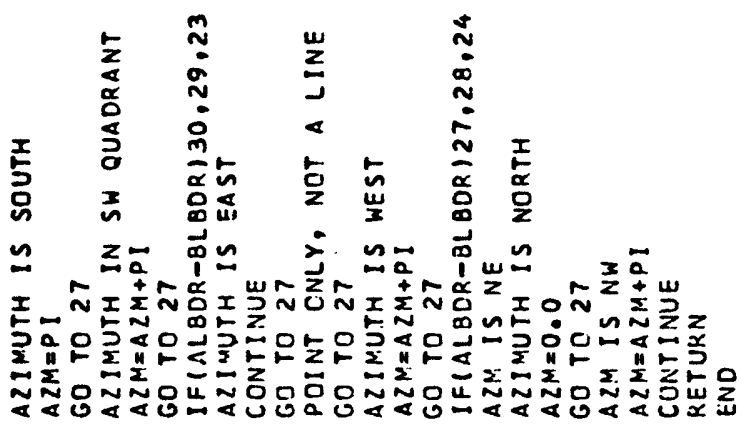

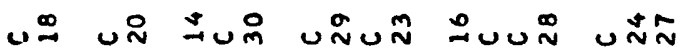

• 